NASA Technical Memorandum 102047

AIAA-89-2357

\title{
Rectangular Nozzle Plume Velocity Modeling for Use in Jet Noise Prediction
}

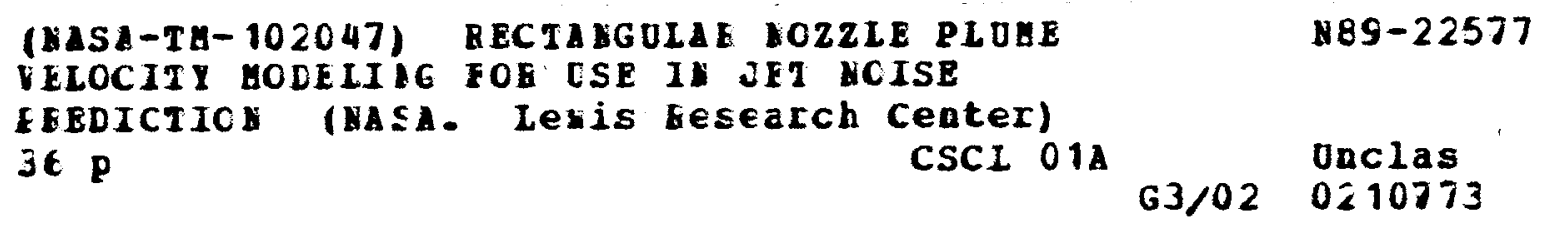

U.H. von Glahn

Lewis Research Center

Cleveland, Ohio

Prepared for the

25th Joint Propulsion Conference

cosponsored by the AIAA, ASME, SAE, and ASEE

Monterey, California, July 10-12, 1989 
RECTANGULAR NOZZLE PLUME VELOCITY MODELING FOR USE IN JET NOISE PREDICTION

\author{
U.H. von Glahn \\ National Aeronautics and Space Administration \\ Lewis Research Center \\ Cleveland, Ohio 44135
}

\title{
Abstract
}

A modeling technique for predicting the axial and transverse velocity characteristics of rectangular nozzle plumes is developed. In this technique, modeling of the plume cross section is initiated at the nozzle exit plane. The technique is demonstrated for the jet plume issuing from a rectangular nozzle having an aspect ratio of 6.0 and discharging into quiescent air. The jet is assumed to be subsonic and operating with cold flow. Application of of the present procedures to a nozzle discharging $\stackrel{m}{F}$ into a moving airstream (flight effect) are then demonstrated. Finally, the effects of plume shear layer structure modification on the velocity flowfield are discussed and modeling procedures are illustrated by example. While some aspects of the present modeling procedure may require some further experimental verification, the trends and general magnitudes of the several effects included in the study are considered appropriate and realistic.

\section{Nomenclature}

$A R$

$\mathrm{De}$

$F, F^{\prime}$ correlation functions defined in text

H rectangular nozzle major axis

h rectangular nozzle or plume height (short) dimensions from centerline

Le acoustic excitation level

M Mach number

$n$ superelliptic plume cross section exponent

$R$ circular nozzle or plume radius

$\mathrm{Se}_{\mathrm{e}}$ excitation Strouhal number

$T$ total temperature

$t$ static temperature

U velocity

W rectangular nozzle major axis

w rectangular nozzle or plume width (long) dimension from centerline

$x \quad$ axial distance from nozzle exit plane

$x_{C} \quad$ core length

$Z$ generic nozzle or plume dimension

$z_{0}^{*} \quad$ nozzle cross section shape factor

\section{Subscripts:}

$\begin{array}{ll}\text { a } & \text { ambient } \\ \text { CL } & \text { centerline } \\ \text { cir circular plume cross section } \\ \text { co core } \\ \text { conv conventional } \\ \text { DP } \quad \text { departure point } \\ \text { FLT flight, freestream } \\ h & \text { nozzle or plume height direction } \\ j & \text { jet exit } \\ m & \text { mixed } \\ \text { mod } & \text { structurally modified plume shear layer } \\ 0 & \text { nozzle } \\ r & \text { radius, radial } \\ \text { STAT } & \text { static } \\ t & \text { static temperature } \\ \text { tot } & \text { total } \\ \text { tran transition } \\ \text { w }\end{array}$

Superscripts:

transverse distance measured from plume core boundary or centerline (downstream of $x_{C}$ )

\section{Introduction}

Future high speed commercial transport (HSCT) aircraft are likely to use asymmetric exhaust nozzles in order to provide enhanced jet noise reduction capability and thereby meet stringent FAA noise regulations, present and future. Compared to circular nozzles, asymmetric nozzles provide more rapid plume velocity decay resulting in lower sound energy output, azimuthal characteristics favorable for the sideline and movement of the peak suppression point to a higher frequency than axisymmetric nozzles. By taking into account the transition duct design from the axisymmetric geometry at the engine turbine exit 
plane to the asymmetric nozzle exhaust plane, as well as size, shape and weight constraints, rectangular nozzles will most likely have nozzle aspect ratios in the range from 2 to 8 . In addition, such nozzles may incorporate treated ejectors in order to further reduce the exhaust plume and turbomachinery noise levels.

In the present study, a global approach is used to develop a modeling procedure for the prediction of rectangular nozzle plume velocity fields of interest in the prediction of high speed jet noise. The present plume modeling technique is initiated at the nozzle exit rather than at an arbitrary downstream axial distance as is presently available in the literature. The initial development herein considers the plume exhausting into quiescent air. An example of the application of the present procedures to the prediction of the plume velocity field for a rectangular nozzle with an aspect ratio of 6.0 is then made. The effect of flight speed and plume shear layer structure modification are then examined and new additional modeling parameters and equations are developed and discussed.

\section{Background}

The primary factors that influence the plume centerline velocity decay are shown schematically in Fig. 1. The decay curves are shown in terms of $U_{C L} U_{j}$ as a function of axial distance from the nozzle exit plane, $x / D_{e}$. The dashed curves in the figure represent the typical trends or variations away from a basic reference curve indicated in the figure by the solid curves.

In Fig. I(a), the effects of an increase in jet static temperature or in jet plume structure modification are shown to cause more rapid plume centerline velocity decay as evidenced by the shift in the decay curve to the left (lower $x / D_{e}$ values) of the reference curve. In Fig. 1(b), the effects of an increase in jet Mach number or flight speed are shown to cause a reduced plume centerline velocity decay, as shown by the shift of the curve to the right of the reference curve (higher $x / D_{e}$ values). While the plume centerline velocity decay trends illustrated in Fig. 1 apply generally to all nozzle shapes, the absolute magnitudes of the curve shifts shown will differ for the several factors, depending on the nozzle cross-sectional shape and flow conditions.

\section{General Modeling Considerations}

In the present modeling technique, the plume velocity flowfield is initiated at the nozzle exit plane. A superellipse concept is used to represent the plume downstream cross sections until a circular cross section is achieved. Thereafter, the plume cross section becomes somewhat elliptical; however, the major and minor axes planes are switched (Refs. 1 and 2). This axes switching can occur several times, especially for nozzles with very high aspect ratios. For rectangular nozzles with an aspect ratio of the order of 8.0 or less, however, the axes of the elliptical shape downstream of the initial circular cross section generally do not differ markedly. Consequently, the plume cross sections herein are considered to be circular at all axial distances downstream of the initial circular cross section location, $X_{c i r}$. For jet noise considerations, this assumption can be justified since at large distances from the nozzle, the plume velocities are relatively low and, consequently, do not contribute significantly to the jet noise signature for most practical considerations.

\section{Dimensional Definitions}

Pertinent nozzle and plume dimensions used in the present modeling procedures are identified in Fig. 2. A generic symbol, $Z$, is used to represent the dimension of interest for a given calculation. Thus, for a circular nozzle/plume, $Z$ represents the transverse dimension or direction denoted by the radius, $R$, of the nozzle or plume. Similarly, for a rectangular nozzle/plume, $Z$ represents the transverse height, $h$, or width, $w$, respectively of the nozzle/plume dimension or direction. Consequently. for general correlations and data plots, the generic symbol $Z$ is used herein. However, where specific data or plots for a plume are shown in a figure or in equations, the appropriate symbol $R, h$, or $w$ is used.

\section{Modeling Synthesis}

The modeling of the plume velocity field for rectangular nozzles consists of five primary steps as follows:

(1) Calculation of the plume centerline velocity decay as a function of the axtal distance from the nozzle exit plane

(2) Calculation of the piume core height and width decay as a function of the axial distance from the nozzle exit plane

(3) Determination of the transverse (radial) half-velocity contour lines of the plume height and width

(4) Determination of the plume transverse velocity contours necessary for establishing the required velocity field.

(5) Application of a superellipse analytical solution developed herein in order to obtain the necessary detailed cross-sectional plume velocity flowfield for noise prediction.

\section{Part I - Static Conditions}

In this section the procedures used to obtain the transverse velocity profiles for rectangular nozzle plumes in static conditions (zero flight speed) will be presented. Included in these procedures will be the determination of the plume center line decay, plume core characteristics, 50-percent velocity contour and the plume velocity at radial (transverse) locations. Finally, examples of plume velocity cross sections (profiles) based on the present correlations and procedures will be presented for several axial locations in the plume.

\section{Plume Centerline Decay}

A schematic depiction of the plume centerline velocity decay with axial distance is shown in fig. 3 for a circular and a rectangular nozzle. The plume centerline velocity decay for a circular nozzle is given by the following equation taken from Ref. 3: 


$$
\frac{U_{C L}}{U_{J}}=\left[1+\left(\frac{x}{6 D_{e} \sqrt{1+M_{j}}}\right)^{8}\left(\frac{t_{j}}{t_{j}}\right)^{2}\right]^{-0.125}
$$

However, for a rectangular nozzle plume centerline velocity decay, with axial distance consists of three basic regions (Ref. 3) as follows:

(1) Initial mixing region

(2) Transition (aka two-dimensional) region

(3) Fully-mixed (aka axisymmetric) region

The departure of the transition region curve from the initial mixing region curve is a function of the plume velocity and temperature (Ref. 3). With an increase in these variables, the departure point shifts to a greater downstream axial distance; however, the slope of the transition region decay curve remains the same. Consequently, the initiation of the fully-mixed region is also shifted to a greater axial distance with an increase in these variables (Ref. 3). Finally, rectangular nozzle centerline velocity decay curves are a function of nozzle aspect ratio, as discussed in Ref. 3 and many other references in the literature.

For rectangular nozzles the plume centerline velocity decay with axial distance can be calculated using the procedures given in Refs. 3 and 4 and summarized as follows:

(1) In the initial mixing region, the plume centerline velocity decay is given in Ref. 3 as:

$$
\frac{U_{C L}}{U_{J}}=\left[1+\left(\frac{X F_{1}}{6 D_{e} \sqrt{1+M_{j}}}\right)^{8}\left(\frac{t_{j}}{t_{a}}\right)^{2}\right]^{-0.125}
$$

where $F_{1}$ is the cross section shape factor given by:

$$
F=1+\frac{1}{9}\left(\frac{D_{e}}{z_{o}^{k}}\right)^{2.5}(A R-1)
$$

The magnitude of $Z_{0}^{*} / D$ e for square and rectangular nozzles is 0.8863 , while for a circular or elliptic nozzle this term is 1.0 . Thus, for an aspect ratio of 1.0 (circular or square nozzle) $F_{1}$ is 1.0 .

(2) In the transition region, the following equations are used to obtain the plume centerline velocity decay:

$$
X_{D P}=\left[\frac{25 D_{e} \sqrt{\frac{T_{j}}{T_{a}}} \sqrt{1+M_{j}}}{F_{1} \sqrt{A R-1}\left(\frac{t_{j}}{t_{a}}\right)^{0.25}}\right]
$$

and

$$
\left(\frac{U_{C L}}{U_{j}}\right)_{\operatorname{tran}}=\left(\frac{U_{C L}}{U_{j}}\right)_{O P} \sqrt{\frac{X_{O P}}{x\left(\frac{t_{j}}{t_{a}}\right)^{0.25} / D_{e} \sqrt{1+M_{j}}}}
$$

where

$$
\left(\frac{U_{C L}}{u_{j}}\right)_{D P}
$$

is the magnitude at $X_{D P}$.

(3) From the data correlation given in Ref. 3 the fully-mixed region centerline velocity decay is obtained with the following equation:

$$
\frac{U_{C L}}{U_{j}}=\left[1+\left(\frac{X F_{2}}{60_{e} \sqrt{1+M_{j}}}\right)^{8}\left(\frac{t_{j}}{t_{j}}\right)^{2}\right]^{-0.125}
$$

In Ref. 3 the correlation parameter, $F_{2}$, is expressed as:

$$
F_{2}=1+\left[\frac{6\left(1-\frac{1}{A R}\right)^{6.0}\left(\frac{T_{j}}{T_{d}}\right)}{A R}\right]
$$

The departure point of the fully-mixed region decay from the transition region is obtained by a simultaneous solution of the transition and fullymixed centerline velocity decay equations. Local values of $U_{C L} / U_{j}$ in the fully-mixed velocity decay region downstream of the departure point can then be obtained with $\mathrm{Eq}$. (6) or by the following simple equation:

$$
\frac{U_{C L}}{U_{j}}=\left(\frac{U_{C L}}{U_{j}}\right)_{D P, m}\left(\frac{x_{D P, m}}{x}\right)
$$

The plume centerline velocity decay curve for a rectangular nozzle with an aspect ratio, AR, of 6 and an equivalent nozzle diameter, $D$, of $7.62 \mathrm{~cm}$ is shown in Fig. 4. The data, taken from Ref. 5, are for a jet Mach number of 0.784 and cold flow. The curve shown in the figure was calculated using the preceding equations. Also shown for comparison in the figure is a curve for the plume centerline velocity decay of a circular nozzle. It is apparent that good agreement between the calculated curves and the data exist for the rectangular nozzle plume. 
General

The hignest level of jet noise emanates from the plume core where the plume velocity is the nighest and is uniform throughout the core volume. In contrast to a circular nozzle plume that has one core, a two-dimensional nozzle effectively has two core regions as shown in Fig. 5. One core region is associated with the height dimension of the nozzle while the other is associated with the width dimension of the nozzle. Herein, it is assumed that the shape or outer boundary of rectangular nozzle plume cores in dimensionless terms is the same as that of a circular nozzle plume core. Consequently, for a given jet flow condition. $R_{c o} / R_{0}$. $h_{c o} / h_{0}$ or $w_{c o} / w_{0}$ as a function of $X / X_{C}$ in the core region are identified by common curves. In the following sections, the symbol $z$ is used to represent $R, h$ and $w$ whenever the equations are common.

The centerline velocity core lengths for both circular nozzle plumes and the height-dimension plume of rectangular nozzles are assumed to terminate at a $U_{C L} / U_{j}$ ratio of 0.99 . However, in the width dimension of rectangular nozzle plumes the core length, based on experiments, traditionally has been assumed to extend to the end of the centerline velocity transition region.

The shape of the core contour with axial distance is frequentily assumed to be a cone for circular nozzle plumes. However, in reality, the cone contour is curved. The local transverse or radial dimension of the core boundary appears to be a function of both jet Mach number and temperature

(Ref. 4) as shown by the data in Fig. 6 .

\section{Core Centerl ine Length}

As stated in the previous section, the plume cores for circular nozzles and the height (narrow) dimension of rectangular nozzles are assumed to terminate at $U_{C L} / U_{j}=0.99$. From $E q$. (2), this leads to the following core length relationships:

Circular nozzle plume. -

$$
x_{C, r}=4.4 \sqrt{1+M_{j}}\left(\frac{t_{a}}{t_{j}}\right)^{0.25}\left(D_{e}\right)
$$

Rectangular nozzle plume. -

(1) Height dimension, $h$ :

$$
x_{C, h}=4.4 \sqrt{1+M_{j}}\left(\frac{t_{a}}{t_{j}}\right)^{0.25}\left(\frac{D_{e}}{F_{l}}\right)
$$

(2) Width dimension, w:

$$
x_{C, w}=\left[1+2(A R-1)^{0.33}\right]\left(x_{C, h}\right)
$$

An alternative to using Eq. (11) involves experimentally establishing the axial location of the intersection of the plume centerline velocity decay curve for the transition and fully-mixed regions ( $F i g .3$ ).

Once the necessary $x_{C}$ distances are determined, the procedures outlined in the next section can be used to establish the core contour or outer shape of this flow region.

\section{Core Contour}

The core contour data shown in Fig. 6 suggest that the data can be correlated by a parameter that includes consideration of both jet Mach number and static temperature. The following relationship. based on data included in Fig. 6, was formulated to yield the core boundaries for both circular and rectangular nozzle plumes:

$$
\frac{z_{c o}}{z_{0}}=\left[1-\left(\frac{x}{x_{c}}\right)^{F_{3}}\right]^{1 / F_{3}}
$$

Data used to determine the exponent $\mathrm{F}_{3}$ are shown in Fig. 7 in terms of $F_{3}-1$ as a function of $M_{j}\left(t_{j} / t_{a}\right)$. A correlation equation for these data is given as follows:

$$
F_{3}=1+0.1\left[\sqrt{M_{j}}\left(\frac{t_{j}}{t_{2}}\right)\right]^{1.33}
$$

Curves based on Eqs. (12) and (13) together with the measured data shown previously in Fig. 6 are shown in Fig. 8. Good agreement between the calculated and measured values is evident for all cases.

\section{0-Percent Velocity Contour}

In order to obtain plume velocity crosssectional plots, the 50-percent contours are generally required in addition to the centerline decay of the plume. These contour lines for a circular nozzle are referenced in the core region to the transverse (radial) core boundary. Downstream of the core region this contour is referenced to the plume centerline. For asymmetric nozzle plumes. the appropriate height and width boundaries of the core are used for reference or initiation of the transverse velocity decay.

In Fig. 9, representative 50-percent velocity contour data are shown as a function of the plume axial distance, $X$. The data shown are for a $7.62 \mathrm{~cm}$ diameter circular nozzle under conditions of cold flow (Ref. 5) and heated flow (Ref. 6). It is evident that in the core region the transverse spread of the 50-percent velocity contour with heated flow is less than that with cold flow for substantially similar jet Mach numbers. Also as discussed previously, the centerline core length is shortened with heated flow compared with that for cold flow. As a consequence, the transverse spreading of the 50-percent velocity contour downstream of the respective core regions for the flow conditions noted in the figure is greater at a given axial location with heated flow than that with cold flow.

The data of Refs. 5 and 6 together with selected data from Ref. 4 provide the foundation and trends for the following 50-percent velocity contour correlation procedures and equations.

In the present correlation procedures, the 50 -percent velocity contour is separated into three 
segments: the core region, a transition region and finally the downstream plume fully mixed spreading region. These segments are shown schematically in Fig. 10, together with the associated core region.

\section{Core Region}

In Fig. 11, the transverse distance from the 50-percent velocity contour to the core boundary for a circular nozzle plume is shown in terms of $R_{0.5 u}-R_{c o}$ as a function of axial distance, $X$. The correlation is based on the transverse (radial) values at the end of the core, $x_{C}$. The correlation for both circular and rectangular nozzles can be expressed as follows:

$$
\left[\frac{\left(z_{0.50}\right)_{x_{C}}-z_{0}}{D_{e}}\right]=0.018 F_{4}\left(\frac{x_{C}}{D_{e}}\right)\left[\frac{m_{j}}{\frac{t_{j}}{t_{a}}}\right]^{0.6}
$$

where

$$
F_{4}=1+\left(\frac{A R-1}{9}\right)
$$

The data shown in Fig. 11 are a function of both jet Mach number and static temperature as well as the axial distance, $X$. The local 50-percent velocity contour is obtained with the following relationship:

$$
\left[\frac{z_{0.5 u}-z_{c 0}}{\left(z_{0.5 u}\right)_{X_{C}}}\right]=1-\left[1-\left(\frac{x}{x_{C}}\right)^{F_{5}}\right]^{1 / F_{5}}
$$

where

$$
F_{5}=1+0.0375 \sqrt{M_{j}}\left(\frac{t_{j}}{t_{a}}\right)^{2}
$$

The curves resulting from the use of Eqs. (16) and (17) are shown in Fig. 12(a) for a circular nozzle for both cold and heated flow conditions. It is apparent that the data are well represented by these equations. Curves for a rectangular nozzle ( $A R=6.0)$ with cold flow are shown in Fig. 12(b). The data and curves in this figure include both the height and width dimensions of the plume. While no heated data are available for a rectangular nozzle plume, by analogy to the circular nozzle cold and heated plume data and the cold flow rectangular nozzle plume data, it can be assumed with a high degree of confidence that Eqs. (16) and (17) al so apply to a rectangular nozzle plume with heated flow.

\section{Transition Region}

For an asymmetric nozzle plume the core length is taken in the narrow dimension of the nozzle and plume: i.e. where $U_{C L} / U_{j}$ first reaches a value of 0.99 . In the present analysis, the correlation of the 50-percent velocity contour in the transition region is based on the variation of $\left(Z_{0} .5 U-Z_{X_{C}}\right) / 0_{e}$ with $\left[\left(x-X_{C}\right)_{Z}\left(t_{j} / t_{a}\right) 0.25 /\left(D_{e} \sqrt{i+M_{j}}\right)\right]$ modified by appropriate nozzle aspect ratio functions. Here, $z$ represents the desired value of the plume dimension $R$ or $h$.

On the basis of the avallable data (Refs. 5 and 6 ), the following equation was developed to provide a reasonable corrulation for the 50-percent velocity contour in the transition region:

$\frac{z_{0.5 U}-z_{X_{C}}}{D_{e}}=0.045 A R^{0.625}\left[\frac{\left(x-x_{C}\right)\left(\frac{t_{j}}{t_{d}}\right)^{0.25}}{D_{e} \sqrt{1+M_{j}}}\right]^{\frac{1.25}{A R^{0.125}}}$

(18)

where $Z=R$ or $h$.

The correlated data using Eq. (18) in the transition region are shown in $\mathrm{Fig}$. 13 for a circular nozzle plume (both cold and heated flows) and a rectangular nozzle plume $(A R=6.0)$. Also included in the figure is the correlation curve based on Eq. (18).

\section{Fully-Mixed Region}

In the fully-mixed region of the plume, the correlation of the 50-percent velocity contour is based on the variation of $\left[\left(Z_{0} .5 y-Z_{c i r}\right) / D_{e}\right]$ and $\left[\left(x-x_{c i r}\right)\left(t_{j} / t_{a}\right) 0.25 /\left(D_{e} \sqrt{1+M_{j}}\right)\right]$ modified also by an appropriate nozzle aspect ratio function. Here the subscript cir denotes the location at which the plume first assumes a circular shape. On the basis of limited available cold flow data (Ref. 5), the following equation was developed to correlate both axisymmetric and asymmetric nozzle plumes:

$\left(\frac{z_{0.5 U}-z_{c i r}}{D_{e}}\right)=0.085 A R^{0.1}\left[\frac{\left(x-x_{c i r}\right)\left(\frac{t_{j}}{t_{a}}\right)^{0.25}}{D_{e} \sqrt{1+M_{j}}}\right]$

As is customary herein, for circular nozzles $Z=R$ and for asymmetric nozzles, such as rectangular nozzles, $z=h$ or $w$.

The correlated data using Eq. (19) are shown in Fig. 14 for a circular nozzle plume and for a rectangular nozzle plume with an aspect ratio of 6.0 . In the latter case, the data scatter about the curve is the result of the assumption that once the plume becomes circular it remains so. In reality, of course, the plume axes tend to reverse one or more times downstream of $x_{c i r}$ as discussed earlier, with the number of reversals apparently increasing with very large nozzle aspect ratios.

The calculated and measured 50-percent velocity contours for a rectangular nozzle with an aspect ratio of 6.0 are shown in $\mathrm{Fig}$. 15. For this example, the equivalent nozzle diameter, $D$, was 
$7.62 \mathrm{~cm}$ and the flow conditions were a jet Mach number of 0.784 and cold flow. In general good agreement between the calculated and measured values was obtained. The data scatter in the fully-mixed region due to the rotation of the plane axes is quite evident. However, for jet noise considerations, the velocity cross sections downstream of $X_{c i r}$ are generally not significant because the velocities associated with these locations may be sufficiently low so as not to influence the jet noise level appreciably.

\section{Transverse Velocity Profiles}

The transverse or radial velocity profiles for single-stream nozzle plumes have been shown to be correlated by the following general equation (Refs. 3, 5, 7, and 8 among many):

$$
\frac{U_{z}}{U_{C L}}=\left\{1-\left[\frac{z^{\prime}}{2.27\left(z_{0.5 U}-z_{c o}\right)}\right]^{1.5}\right\}^{2.0}
$$

where $U_{Z}$ is the local piume transverse velocity and 2 ' is measured from the core boundary in the core region and from the plume centerline downstream of the core. Also $Z^{\prime}=R^{\prime}$ or $h^{\prime}$ or $w^{\prime}$.

With Eq. (20), the following relationships are obtained for circular and rectangular nozzle plumes:

(1) Circular nozzles. -

$$
R^{\prime}=2.27\left(R_{0.5 U}-R_{C O}\right)\left(1-\sqrt{\frac{U_{r}}{U_{C L}}}\right)^{0.667}
$$

and

$$
R_{\text {tot }}=R_{\text {co }}+R^{\prime}
$$

(2) Rectangular nozzles. -

Nozzle height plane, $h$ :

$$
h^{\prime}=2.27\left(h_{0.5 U}-h_{C O}\right)\left(1-\sqrt{\frac{U_{h}}{U_{C L}}}\right)^{0.667}
$$

and

$$
h_{\text {tot }}=h_{\text {co }}+h^{\prime}
$$

Nozzle width plane, w:

$$
w^{\prime}=2.27\left(w_{0.5 U}-w_{C O}\right)\left(1-\sqrt{\frac{U_{w}}{U_{C L}}}\right)^{0.667}
$$

and

$$
w_{\text {tot }}+w_{\text {co }}+w^{\prime}
$$

Typical transverse velocity profile data for a circular and a rectangular nozzle plume are shown in Figs. 16 and 17 , respectively. The data are well represented by the curves shown in the figures which were obtained by use of the preceding equations. Further details and data on transverse velocity profiles are included in Ref. 3 . It should be noted that all transverse velocity proflles, in terms of $Z^{\prime}$ are independent of nozzle or plume shape.

\section{Transformation of Plume Cross Section}

The transformation of the plume cross section from rectangular at the nozzle exit plane to circular at some distance downstream where the major and minor axes of the plume are equal is achieved by using a superellipse concept. The superellipse technique is developed as follows:

(1) At a given axial location in the plume, the generai superellipse equation for a specific velocity location in the plume is given by:

$$
h=h_{\text {tot }}\left[1-\left(\frac{w}{w_{\text {tot }}}\right)^{2}\right]^{n}
$$

where $h$ and $w$ are local values on the ellipse.

In Eq. (27), the $h_{\text {tot }}$ and $w$ tot are the minor and major axes of the elifpse and are related to the height and width, respectively, of the rectangular nozzle and plume.

(2) The exponent $n$ in Eq. (27) varies from 0 at the nozzle exit plane to 0.5 where $h=w$ (i.e.. the plume cross section is (ircular). Herein, the n-exponent is assumed to vary linearly with axial distance: consequentiy.

$$
n=0.5\left(\frac{x}{x_{\text {cir }}}\right)
$$

Once a circular cross section has been established, $h_{\text {tot }}=w_{\text {tot. }}$. It should be noted that the n-exponent may not actually be linear with axial distance. Thus further work is needed to establish the actual variation of $n$ with $x$ and determine its significance on the plume cross-sectional development.

An example of the cross-sectional changes provided by the use of the n-exponent is illustrated in Fig. 18. In Fig. 18(a), one quarter of a circle is shown. The circle has the conventional n-exponent of 0.5 . The dashed line at $w=0.9$ indicates the region in which the effect of a variation of $n$ on the cross section will be examined. In Fig. 18(b), the various contours obtained with several different values of $n$ are shown for $w$ greater than 0.9. Note than when $n=0$, the circle is transformed into a square. For $n$ greater than 0 and less than 0.5, various superellipses are. Similar trends are obtained when the initial cross section is a rectangle instead of a square.

\section{Application of Modeling Technique}

General

The plume modeling techniques developed in the preceding sections are now applied to develop several plume velocity cross sections for a rectangular nozzle with an aspect ratio of 6.0 . As in Ref. 5 , a jet Mach number of 0.784 and cold flow was selected for the example. Also, a nozzle equivalent diameter 
of $7.62 \mathrm{~cm}$ was chosen. The calculated plume centerline velocity decay for the example is shown in

Fig. 4. The calculated 50-percent velocity contours for the minor axis, $h$, and the major axis, w, are shown in Fig. 19. The intersection of the two contours $\left(X_{c i r}\right.$ ) occurs at a nominal axial distance of $123.7 \mathrm{~cm}$. Also shown in the figure is the variation of the n-exponent with axial distance. Finally the axial locations for which plume velocity cross sections were developed are shown by the arrows at the top of the figure.

\section{Representative Plume Cross Sections}

Typical plume velocity cross sections at nominal axial distances of $12.7,27.3,41.3,57.2$, 82.6 , and $123.7 \mathrm{~cm}$ are shown in $\mathrm{Fig} .20$. Note that the height core ends at about an axial distance of $27.3 \mathrm{~cm}$ and the plume becomes circular at an axial distance of about $123.7 \mathrm{~cm}$. After the height core ends, the width core suggests a line source distribution; i.e., $U_{w} / U_{C L}=1.0$ is a line source that decreases in width with increasing axial distance until the end of the width core is reached. With increasing downstream distance, the contours change from a rectangular cross section at the nozzle exit to elliptic and finally to a circular cross section. Downstream of $X_{c i r}$ all cross sections are assumed herein to be circular, with the local velocity radii increasing with axial distance.

\section{Part II - Flight Effects}

The interaction of a secondary stream or flight effect with a plume has been studied since at least 1950 (Refs. 7 and 8 ). The effect of flight on the core and 50-percent velocity contour in the nozzle height dimension is shown schematically in Fig. 21. Also shown for comparison in the figure are the corresponding curves for static conditions (no external flow). As shown in the figure, in flight the core is lengthened (reduced axial decay rate), $\left(X_{C}\right) F L T$ ) $\left(X_{C}\right)_{\text {STAT, and the plume becomes circular at a }}$ greater axial distance than the corresponding distance for a static condition. Similar trends are noted in the nozzle width dimension.

\section{Plume Centerline Decay}

The effect of flight on the plume centerline velocity decay was correlated in Ref. 9 with the following equation:

$$
F_{F L T}=1+\left[\frac{0.725(\text { AR })^{1 / 3}\left(\frac{U_{F L T}}{U_{j}}\right)^{4 / 3}}{\left(1-\frac{U_{F L T}}{U_{j}}\right)^{1 / 8}}\right]
$$

For $U_{F L T} / U_{j}$ less than 0.8 , a simplified equation yielding substantially the same result was also suggested in Ref. 9, as follows:

$$
F_{F L T}^{\prime}=1+0.9(A R)^{1 / 3}\left(\frac{U_{F L T}}{U_{j}}\right)^{3 / 2}
$$

These parameters are used to modify the axtal distance for static conditions as discussed in the next sections.

The correlation of the rectangular nozzle plume centerline velocity decay using the relationship of Eq. (29) is shown in Fig. 22 for several flight conditions. The data were taken from Refs. 10 and 11 and correlated in Ref. 9. It is apparent that Eq. (29) correlates the data satisfactorily.

\section{Core Centerline Length}

In flight conditions, the core centerline length is obtained by multiplying the appropriate core centerline length in static conditions (Eqs. 9 to 11 ) by $\mathrm{Eq}$. (29) or (30), as follows:

$$
\left(X_{C}\right)_{F L T}=\left(X_{C}\right)_{S T A T}\left(F_{F L T} \text { or } F_{F L T}^{\prime}\right)
$$

\section{Core Contour}

The core contour in flight is determined by the same procedures as those used in static conditions. Once the core centerline length in flight, $\left(X_{C}\right)^{\prime}$ FLT, has been determined, Eqs. (12) and (13) are used to obtain the core contour in flight. In order to accomplish this, the calculated $\left(X_{C}\right)_{F L T}$ is used in place of the static value of $x_{C}$ in these equations.

\section{0-Percent Velocity Contour}

\section{Core Region}

In the core region, the flight effect on the 50-percent velocity contour is accounted for by the inclusion of the factors expressed by Eq. (29) or (30) in the static core region equation. Consequently, the transverse values in flight at the end of the core region are given by:

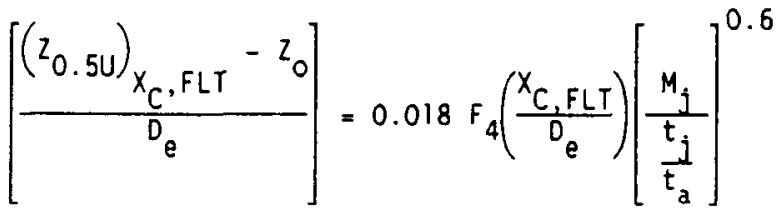

In a similar manner, the local 50-percent velocity contour values are obtained with the following relationship:

$$
\left[\frac{z_{0.5 U}-z_{C O}}{\left(z_{0.5 U}\right)_{X_{C}}}\right]_{F L T}=1-\left[1-\left(\frac{x}{X_{C}}\right)_{F L T}^{F_{5}}\right]^{1 / F_{5}}
$$

\section{Transition Region}

The 50-percent velocity contour in flight conditions is obtained with the following equation: 


$$
\begin{aligned}
\left(z_{0.5 U}-z_{X_{C}}\right)_{F L T}= & {\left[\frac{0.045 D_{e}\left(x_{C}\right)_{S T A T}}{\left(x_{C}\right)_{F L T}}\right]_{A R}^{0.625} } \\
& \cdot\left[\frac{\left(x-x_{C}\right)_{F L T}\left(\frac{t_{j}}{t_{2}}\right)^{0.25}}{D_{e} \sqrt{1+M_{j}}}\right]
\end{aligned}
$$

\section{Fully-Mixed Region}

In the fully-mixed region of the plume, the 50 -percent velocity contour in flight conditions can be expressed as follows:

$$
\begin{aligned}
\frac{z_{0.5 U}-z_{c i r}}{\left(D_{e}\right)_{F L T}} & =\left[\frac{0.085\left(x_{C}\right)_{S T A T}}{\left(x_{C}\right)_{S T A T}}\right] A R^{0.1} \\
& {\left[\frac{\left(x-x_{c i r}\right)_{F L T}\left(\frac{t_{j}}{t_{a}}\right)^{0.25}}{D_{e} \sqrt{1+M_{j}}}\right] }
\end{aligned}
$$

\section{Plume Transverse Decay}

The overall plume transverse decay or spreading at a given axial location is decreased in flight compared with static conditions (Ref. 9). However, in nondimensional terms the transverse velocity decay is independent of flight effects as shown in Fig. 23. The data shown are for the nozzle height dimension, $h$, of a rectangular nozzle having a noz$z$ le aspect ratio of 24 and were taken from Ref. 11 . In Fig. 23(a), the plume transverse velocity decay is shown for several UFLT/Uj ratios at a nominal $X / D_{e}$ of 2.7. The plume transverse velocity decay curve for a circular nozzle is also shown for comparison. It is apparent that the two nozzle plume types have similar velocity decay characteristics in nondimensional terms. In Fig. 23(b), the plume transverse velocity decay for the same rectangular nozzle is shown for several $x / D$ e locations at a constant $U_{F L T} / U_{j}$ ratio of 0.5 . Also shown for comparison again is the decay curve for a circutar nozzle plume. The plume transverse velocity data for the rectangular nozzle plume coincides with that for the circular nozzle plume transverse velocity decay at all $x / D_{e}$ locations.

As noted in the discussion of Fig. 21 , several basic considerations are taken into account in determining the 50-percent velocity transverse contours in flight conditions. These considerations include an extension of the core region and an overall less rapid plume transverse expansion compared with those for static conditions. As a consequence, the axial distance at which the rectangular nozzle plume becomes circular in cross section is greater in flight than that in a static condition.

The transformation of the plume cross section from rectangular to circular in a flight condition is accomplished by applying the same procedures as those developed for static conditions (Eqs. 27 and 28).

\section{Application of Modeling Technique}

The plume velocity decay modeling technique in a flight condition is now lllustrated for an elongation of the static plume core, $X_{C}$, by 50-percent due to flight. The nozzle operating conditions in flight are assumed to be the same as those previousiy used for the static calculations in the preceding sections (namely: $M_{j}, 0.784 ; D_{e}, 7.62 \mathrm{~cm}$; cold flow).

\section{Centerline Velocity Decay}

The calculated plume centerline velocity decay curve in flight is shown in Fig. 24 for a rectangular nozzle having an aspect ratio of 6.0 . Also shown in the figure, for comparison, is the decay curve for a static condition. It is evident that the effect of flight is to shift the decay curve to the right in the figure thereby increasing the axial extent of the plume.

\section{0-Percent Velocity Contour}

Using Eqs. (32) to (35) the plume 50-percent velocity contours were calculated for the flight condition. The resulting curves for the plume height, $h$, and plume width, w, are shown in Fig. 25. Also included in the figure is the axial variation of the n-exponent needed to calculate the plume cross sections at the desired axial locations. Finally, the plume cross sections in static conditions are also shown for comparison. It is apparent that the effect of flight causes an axial extension of the contours and that, consequently, the axial location at which the transverse cross sections become circular also occurs at a greater downstream distance in flight compared with that for static conditions.

\section{Plume Cross Sections}

From the plume centerline and 50-percent velocity contours the local plume cross sections in flight can be calculated using the same general procedures as those used for static conditions. However, in flight conditions the appropriate flight parameters are used in place of the static condition parameters. From such calculations, cross sections similar to those shown in Fig. 20 are obtained for flight conditions.

\section{Part III - Plume Structure Modification}

A more rapid plume centerline, core and transverse velocity decay can be achieved by altering the large-scale structure in the plume shear layer (Ref. 12). As has been demonstrated in the literature, this plume shear layer structural modification can be achieved by acoustic, thermal and aeromechanical means. For the most part, the published data have been obtained with cold flow and heated flow axisymmetric nozzle plumes in both static and flight environments. However, limited data suggests that similar results have been obtained with asymmetric nozzle plumes.

The effect of modifying the plume shear layer structure on the velocity core and 50-percent contours is shown schematically in Fig. 26 for a rectangular nozzle plume. Also shown in the figure 
for comparison are the corresponding curves for a conventional plume. It is apparent from the figure that the core length is reduced and the axial length needed for the 50-percent velocity contour to become circular is also shortened when the plume shear layer is structurally modified. While the trends shown in the figure are in the plume height plane, similar trends also apply in the plume width plane.

\section{Plume Centerline Velocity Decay}

Plume centerline velocity decay data in static conditions for structurally modified plumes are presented in Refs. 12 to 16, among many in the iiterature. In Fig. 27, the effect of structurally modifying the plume shear layer by acoustic excitation on the cold flow plume centerline velocity decay for static and flight conditions is shown as a function of axial distance, $X$, (Ref. 14). With a structurally modified plume, the velocity decays more rapidly with axial distance than with a conventional plume. Other means of modifying the plume structure (for example, mechanical fingers or tabs) can cause similar effects.

Efforts to correlate structurally modified (acoustically excited) plume centerline velocity decay data are reported in Refs. 14 to 16, among others in the literature. In Ref. 16 it was shown that the correlation of the data was a complex function of jet velocity, temperature, acoustic power level and acoustic excitation Strouhal number. For nonacoustic means of modifying the plume shear layer structure, the functions appear to be much less complex. In particular, when flow turbulators are used, it appears that the jet temperature is not a major factor in the shear layer modification. It is apparent, however, that further work is needed in order to provide sufficient understanding for successful application of plume structural modification means to full-scale engine exhaust flows.

\section{Core Centerline Length}

Tentative correlations that account for the structural modification of the plume shear layer to reduce the core length are included in Refs. 9, 14 and 16 . These correlations were developed for acoustically excited plume shear layers. The correlated core length for a structurally modified plume, herein designated $\left(X_{C}\right)_{\text {mod, }}$ is obtained by dividing the unmodified core length for static conditions (Eqs. (9) to (11)) by the appropriate correlation parameters developed in these references.

\section{Core Contour}

Once the term $\left(X_{C}\right)_{\text {mod }}$ has been determined, the core contour for a structurally modified plume in static conditions is established in the same manner as that for an unmodified plume. Thus, Eqs. (12) and (13) are used to obtain the core contour with $\left(X_{C}\right)_{\text {mod }}$ substituted for the conventional (unmodified) $x_{C}$.

\section{0-Percent Velocity Contour}

The 50-percent velocity contours for a structurally modified plume are developed by the same procedures used for conventional plumes and outlined in Part I; however, the applicable dimensions and parameters for the structurally modified plume are substituted where appropriate for the conventional plume dimensions and parameters.

\section{Plume Transverse Velocity Decay}

Representative transverse velocity decay for a structurally modified plume is shown in Fig. 28 for a circular nozzle. Also shown in the figure is a curve for a conventional plume. In nondimensional parameters, the structurally modified plume decay data are shown to coincide with the conventional velocity decay curve. It was also shown in Ref. 9 that the conventional rectangular nozzle transverse velocity decay data colncided with the conventional circular nozzle plume curve. Consequently, it was assumed in Ref. 9 and here in that, by analogy, rectangular nozzle transverse velocity decay characteristics and trends for structurally modified plumes also coincide with the curve shown in Fig. 28 . This analogy is also assumed herein to apply in flight conditions (see also Ref. 9).

As a result of the reduced plume core length and more rapid transverse spreading of the structurally modified plume, the axial distance at which the plume becomes circular in either static or flight conditions is reduced from that without plume structural flow modification.

The transformation of the plume cross section from rectangular to circular for structurally modified plumes is accomplished using the same procedures as those used for conventional plumes but, as discussed previously, using the applicable parameters for structurally modified plumes.

\section{Application of Modeling Technique}

The modification of the plume modeling technique developed for conventional nozzle plumes to that for structurally modified plumes is now illustrated with an example for which the modification is assumed to cause a plume core axial reduction of 50-percent in the height plane. The nozzle flow conditions are assumed to be the same as those previously used for both the static and flight examples.

\section{Centerline Velocity Decay}

The calculated centerline velocity decay curve for the structurally modified plume in static conditions is shown in Fig. 29. Also shown in the $\mathrm{fig}$ ure, for comparison purposes, is the decay curve for a conventional plume. It is evident that the structural modification of the plume caused a shift to the left from the conventional plume curve, indicating a more rapid decay of the plume in the axial direction.

\section{0-Percent Velocity Contour}

Using the procedures developed in Part I, the structurally modified plume transverse velocity contours were developed. The resulting curves for the height and width planes of the nozzle plume are shown in Fig. 30. Also shown in the figure for comparison are the curves for a conventional piume. The n-exponents for both cases are also shown in the figure as functions of axial length, $x$. The reduction in core length and the consequent more rapid spreading of the plume downstream of the core with shear layer structural modification compared 
with a conventional plume are quite evident in the figure. Similar trends, not shown, will occur in fight.

\section{Plume Cross Section}

From the plume centerline decay and the 50-percent velocity contours, the cross sections of the structurally modified plume can be calculated by the same procedures used for conventional plume cross sections. However, the modified plume parameters are used. where appropriate, in place of the conventional plume parameters. With this procedure, cross sections similar to those shown previously in Fig. 20 can then be developed. As discussed earlier, with a structurally modified plume, the axial location of the initial circular cross section will occur in a shorter axial distance than that with a conventional plume. While not shown herein, in flight conditions similar trends to those obtained with conventional plumes will be obtained with structurally modified plumes.

\section{Concluding Remarks}

The empirical analyses used herein are, in part, based on very limited data. Additional data are needed to verify some of the assumptions included in this study. In particular the parameters in which nozzle aspect ratio is included as a variable must be further examined and validated for aspect ratios other than 6.0. Also, the assumption that the axial variation of the cross section n-exponent is linear must be verified. While a nonlinear n-exponent would change the plume cross sections included herein, it is believed that any reasonable nonlinearity in this exponent would not seriously impact the general shapes of the local plume cross sections. Consequently, such a change to a nonlinear exponent also would not alter significantly the jet noise signature.

The preceding sections, Parts I to III, can be combined to obtain rectangular nozzle velocity plumes from which jet noise signatures can be developed for future high speed commercial transport aircraft. The basic plume characteristics in static conditions can be expanded to include the effects of flight and plume shear layer structure modification. The result of including these considerations, in general, will cause a change in both the plume length and spreading rate. The increase in plume length due to flight may, in part, be offset by plume structure modification means based on current technology. It is apparent from this brief synopsis that the specific plume modifications caused by these factors depend on the particular exhaust nozzle design, propulsion system operating conditions and the means used to modify the plume shear layer structure. While some aspects of the present modeling procedures may require further experimental verification, the trends and general magnitudes of the several effects included in this study are considered appropriate and realistic.

\section{Conclusions}

On the basis of the present study concerned with rectangular nozzle plume velocity decay characteristics, the following results are summarized and conclusions are drawn:
1. Procedures were developed that can be used to empirically correlate plume axial velocity decay and transverse spreading in static conditions. The correlations are based in part on and extended from work available in the literature.

2. A modeling procedure was developed that permits the velocity plume from a rectangular nozzle to be transformed into a circular cross section some distance downstream of the nozzle exit plane. The axial length for this to occur is determined primarily by the nozzle aspect ratio and the jet flow conditions. The transformation of the plume from rectangular to circular in cross section is initiated at the nozzle exit olane and employs a superellipse modeling procedure.

3. The plume correlation procedures for static conditions are extended to include the expected effects of flight and plume shear layer structure modification by appropriate parametric functions.

4. The separate correlation procedures developed for static, flight and plume structure modification effects can be combined for use in predicting aircraft jet noise signatures.

\section{References}

1. Saheli, F.P., "Experimental and Analytical Evaluation of Three-Dimensional Exhaust Plumes," AIAA Paper 80-1399, July 1980.

2. Sforza, P.M., Steiger, M.H., and Trentacosta, N. "Studies on Three-Dimensional Viscous Jets," AIAA Journal, Vol.4, No.5, May 1966, pp.800-806.

3. von Glahn, U.H., "Two-Dimensional Nozzle Plume Characteristics," AIAA Paper 87-2111. June 1987 (NASA TM-8981.).

4. von Glahn, U., "On Some Flow Characteristics of Conventional and Excited Jets," AIAA Paper 84-0532, Jan. 1984. (NASA TM-83503.)

5. Higgins, C.C., and Wainwright, T.W., "Dynamic Pressure and Thrust Characteristics of Cold Jets Discharging from Several Exhaust Nozzles Designed for VTOL Downwash Suppression, "NASA TN D-2263, 1964.

6. Higgins, C.C., Kelly, D.P., and Wainwright, T.W., "Exhaust Jet Wake and Thrust Characteristics of Several Nozzles Designed for VTOL Downwash Suppression," NASA CR-373, 1966.

7. Landis, F. and Shapiro, A.H., "The Turbulent Mixing of Co-Axial Gas Jets, "Proceedings of the Heat Transfer and Fluid Mechanics Institute, Stanford University Press, Stanford, CA, 1951, pp. 133-146.

8. Forstall, W.. Jr., and Shapiro, A.H., "Momentum and Mass Transfer in Co-Axial Gas Jets," Journal of Applied Mechanics, Vol.17, No.4, Dec. 1950, pp. 399-408.

9. von Glahn, U.H., "Secondary Stream and Excitation Effects on Two-Dimensional Nozzle Plume Characteristics," AIAA Paper 87-2112, June 1987. (NASA TM-89813.) 
10. Forthmann, E., "Turbulent Jet Expansion," NACA $T M-789,1936$.

11. Weinstein, A.S., Osterle, J.F., and Forstall, W. "Momentum Diffusion from a slot Jet Into a Moving Secondary." Journal of Applied Mechanics. vol. 23, No.3, Sept. 1956, pp.437-443.

12. Ahuja, K.K., Lepicovsky, J., Tam, C.K.W., Morris, P.J., and Burrin, R.H., "Tone-Excited Jet: Theory and Experiment." NASA CR-3538, 1982.

13. Vulis, L.A., "Turbulent Mixing of Free Gas Jets," Fluid Mechanics-Soviet Research, Vol.1, No. 3, May-June 1972, pp.130-135.
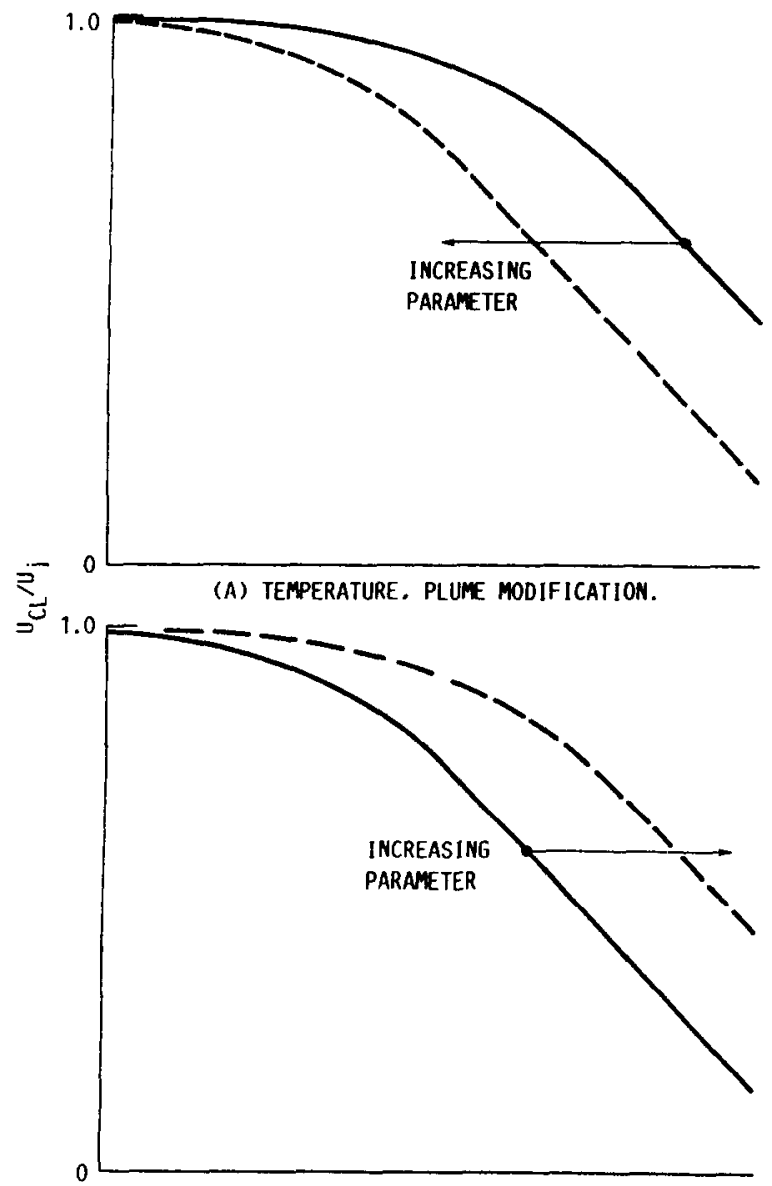

(B) JET MACH NUMBER, FLIGHT

$$
\mathrm{X} / \mathrm{D}_{\mathrm{e}} \longrightarrow
$$

FIGURE 1. - SCHEMATIC REPRESENTATION OF THE EFFECT OF SEVERAL PARAMETERS ON PLUME CENTERL INE VELOCITY DECAY.
14. von Glahn, U.H., "Correlation of Flight Effects on Centerline Velocity Decay for Cold-Flow Acoustically Excited Jets," NASA TM-83502, 1983.

15. von Glahn, U.H., "Preliminary Analysis of Tone-Excited Two-Stream Jet Velocity Decay," NASA TM-86951, 1985.

16. von Glahn, U.H., "On the Correlation of Plume Centerline Velocity Decay of Turbulent Acoustically Excited Jets." AIAA Paper 87-2692. Oct. 1987 (NASA TM-100193).
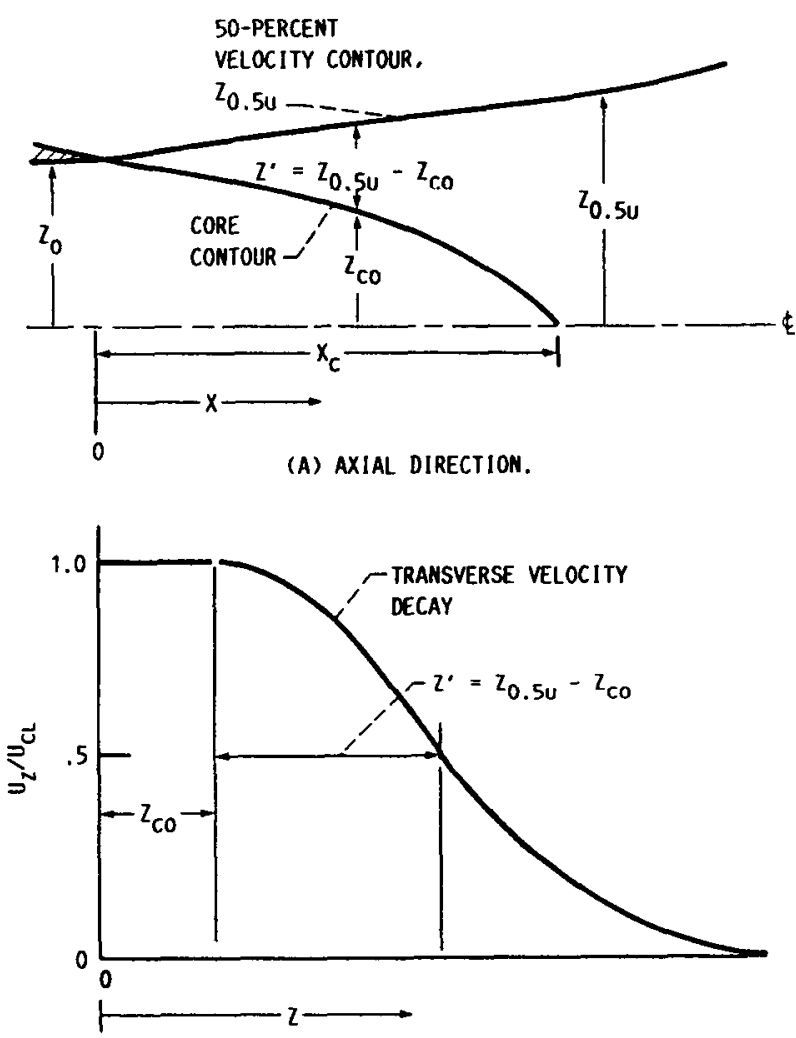

(B) TRANSVERSE (RADIAL) DIRECTION.

FIGURE 2. - GENERIC NOZZLE/PLUME COMPONENT AND FLOW DEFINITIONS. 


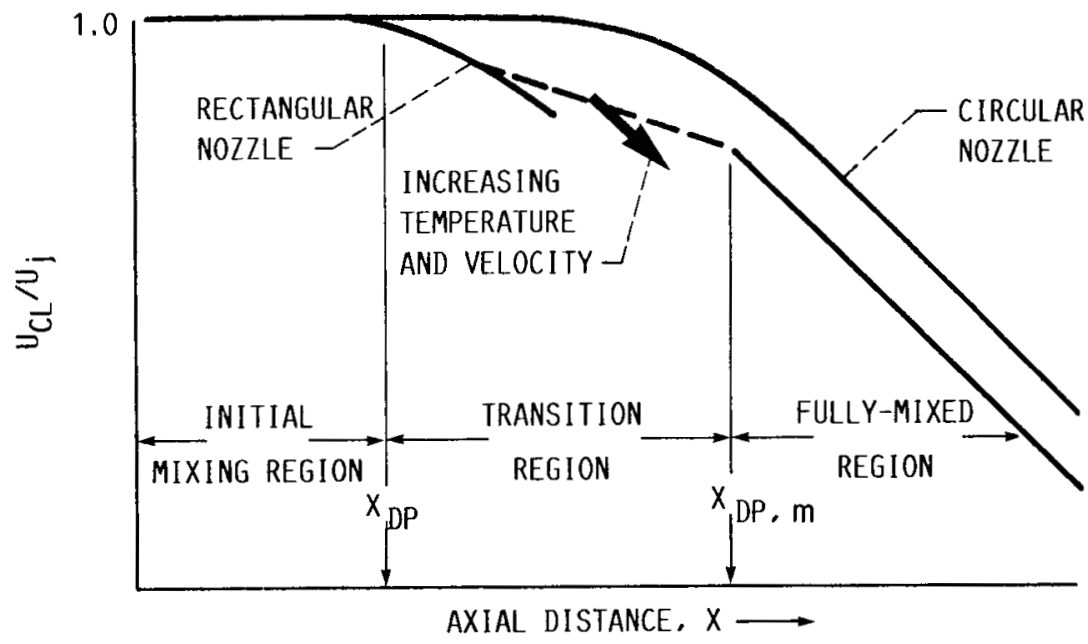

FIGURE 3. - SCHEMATIC SKETCH OF PLUME CENTERLINE VELOCITY DECAY.

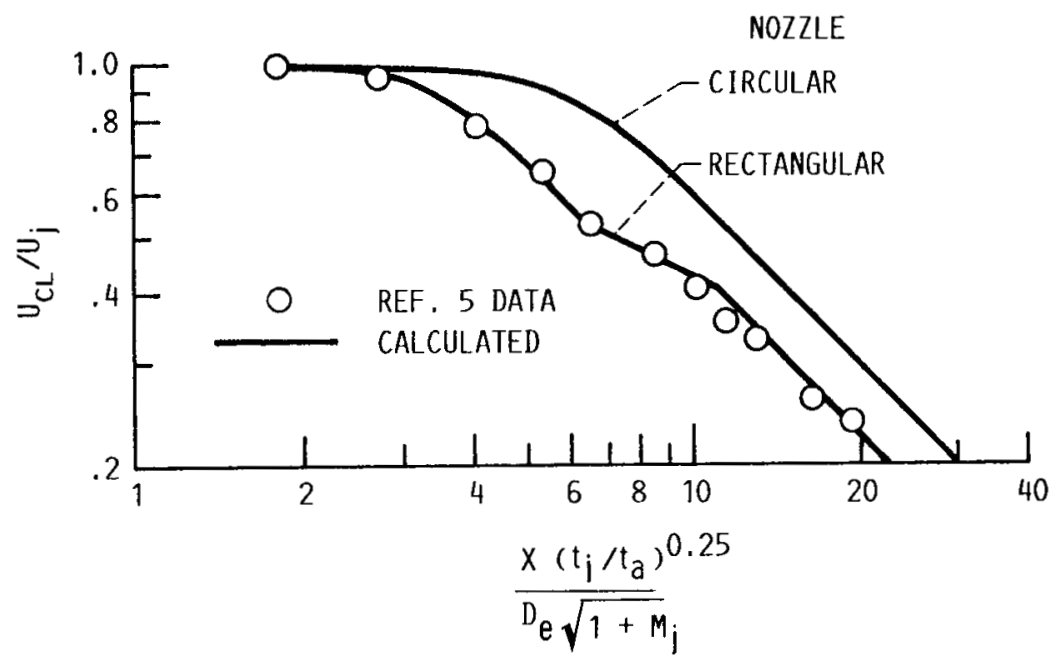

FIGURE 4. - PLUME CENTERLINE VELOCITY DECAY FOR CIRCULAR AND RECTANGULAR (AR $=6$ ) NOZZLES. COLD FLOW: $M_{j}, 0.784$; $\mathrm{D}_{\mathrm{e}} \cdot 7.62 \mathrm{cM}$. 


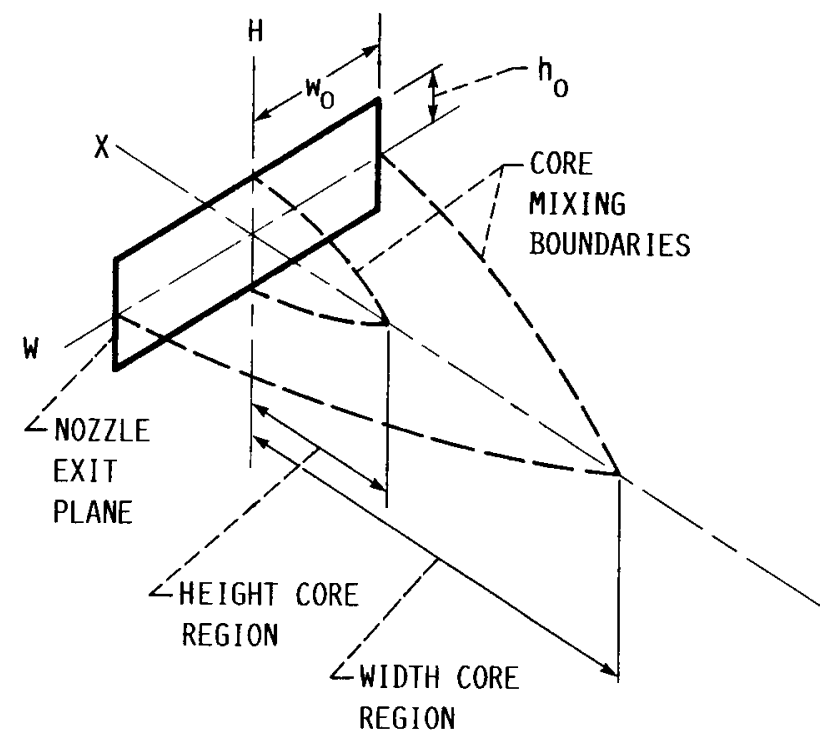

FIGURE 5. - SCHEMATIC SKETCH OF PLUME CORE REGIONS FOR RECTANGULAR NOZZLES. 


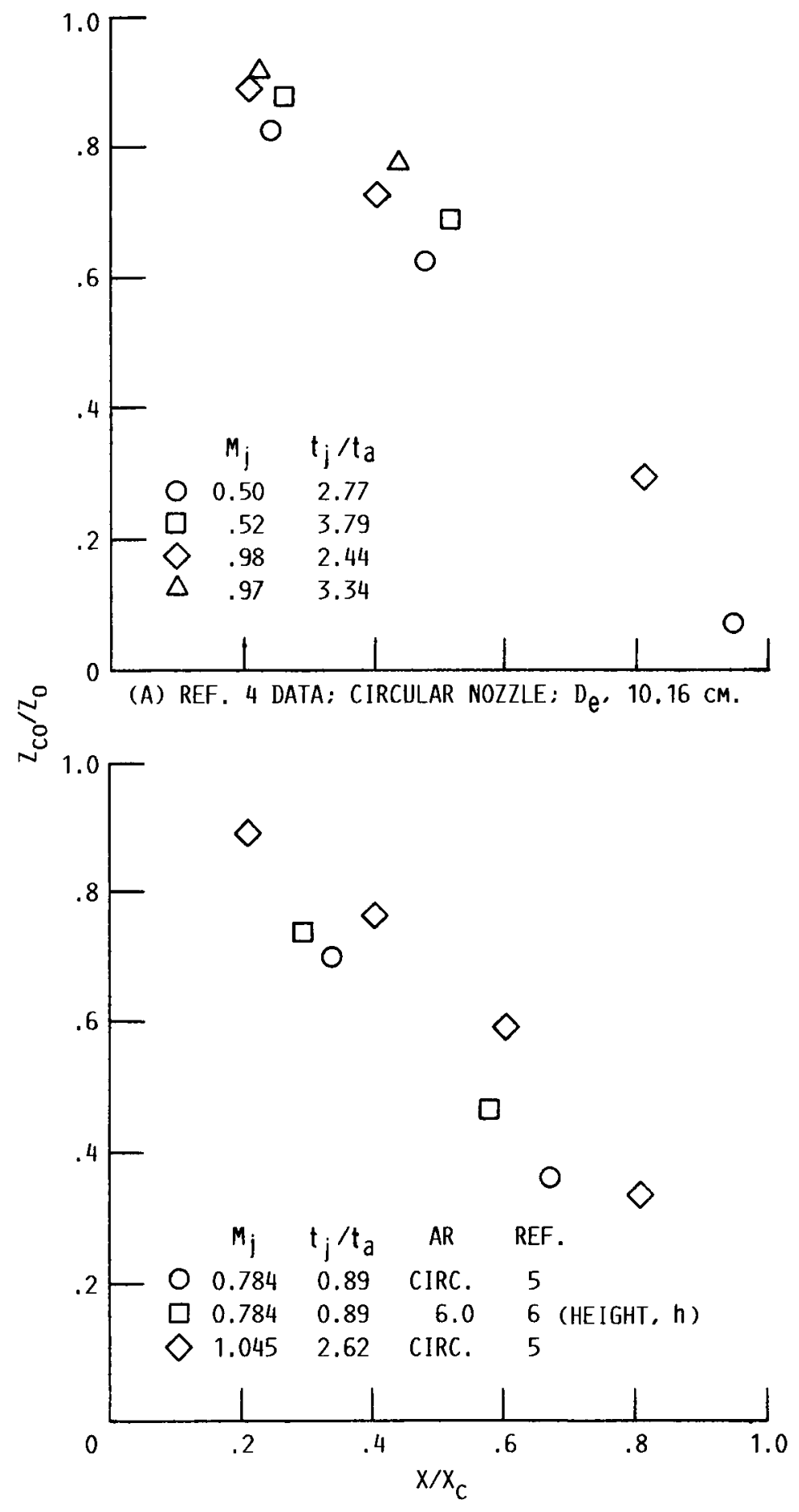

(B) $D_{e}, 7.62 \mathrm{~cm}$.

FIGURE 6. - PLUME VELOCITY CORE CONTOUR DATA. 


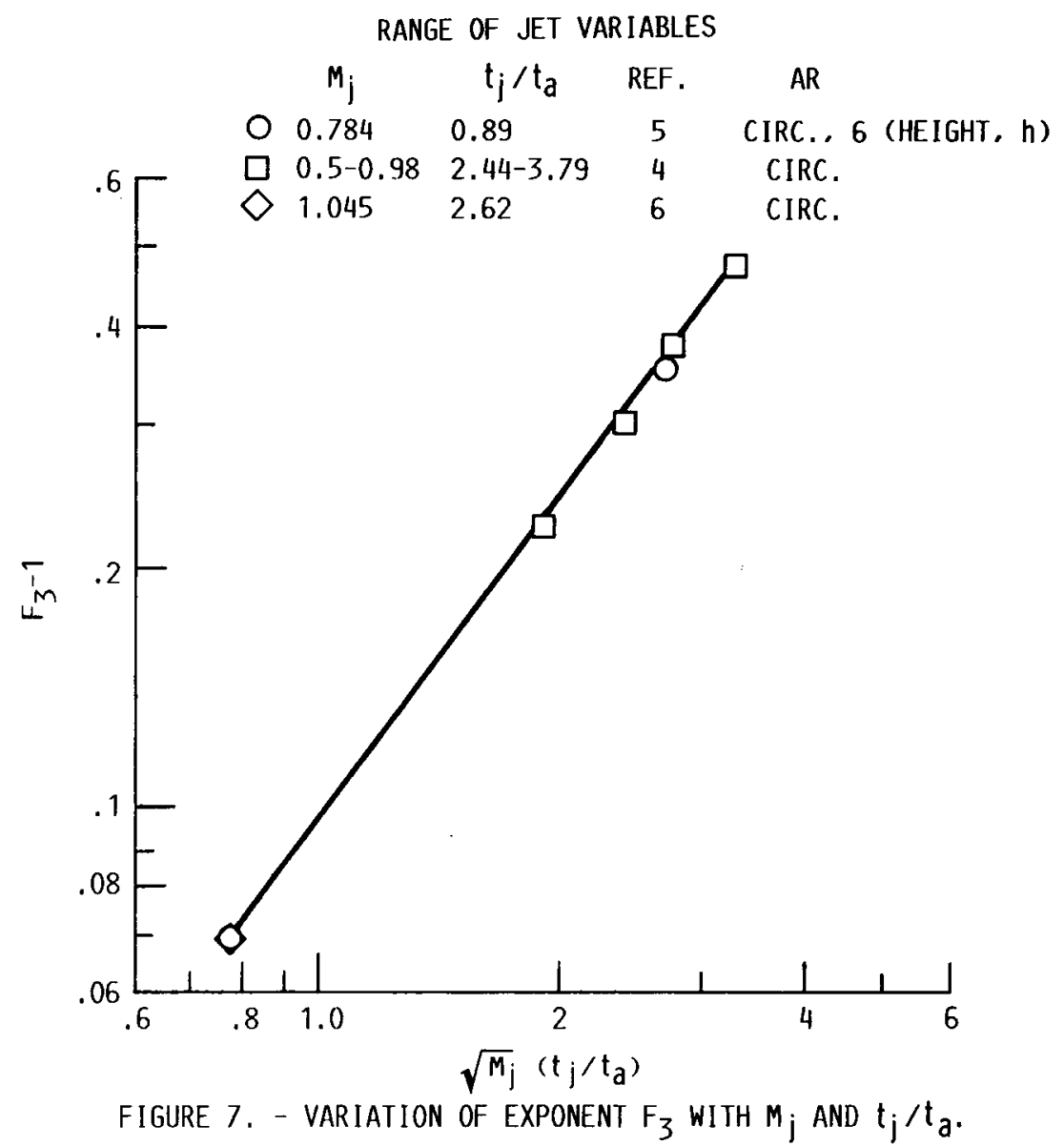




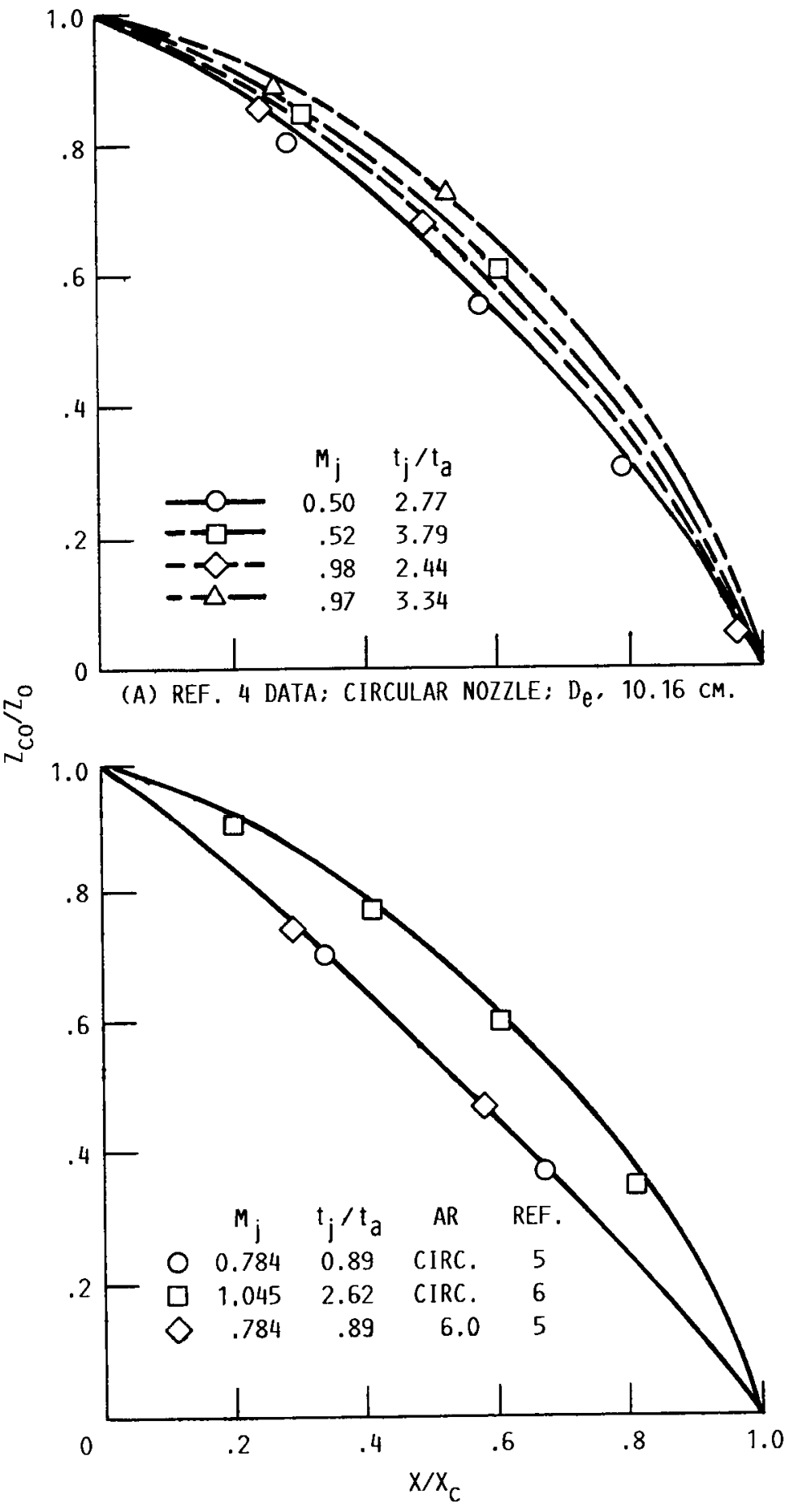

(B) $\mathrm{D}_{\mathrm{e}} \cdot 7.62 \mathrm{cM}$.

FIGURE 8. - COMPARISON OF CALCULATED CORE CONTOUR CURVES WITH MEASURED DATA. 


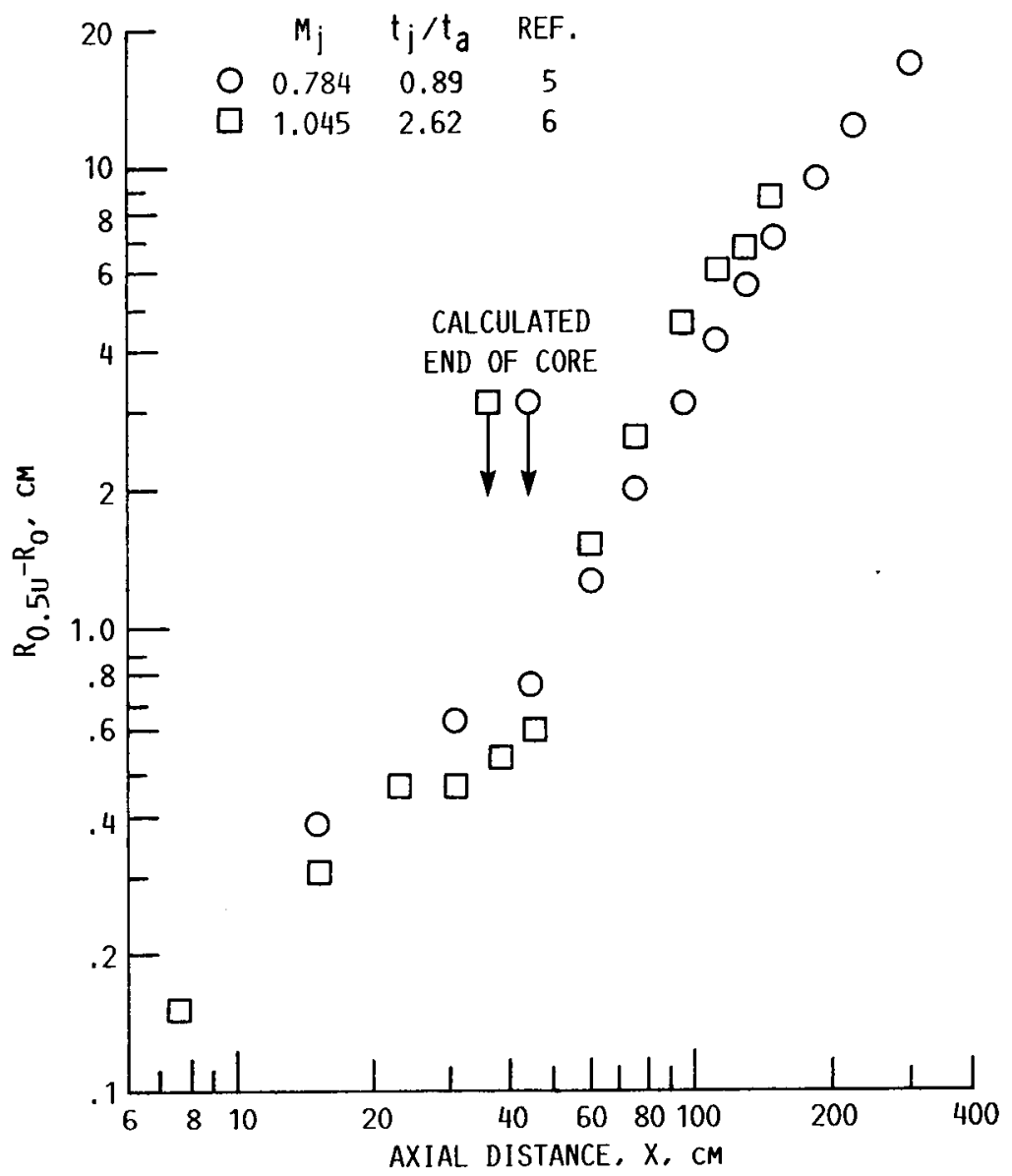

FIGURE 9. - 50-PERCENT VELOCITY CONTOURS FOR COLD AND HOT CIRCULAR NOZZLE PLUMES, $D_{\mathrm{e}}, 7.62 \mathrm{~cm}$. 


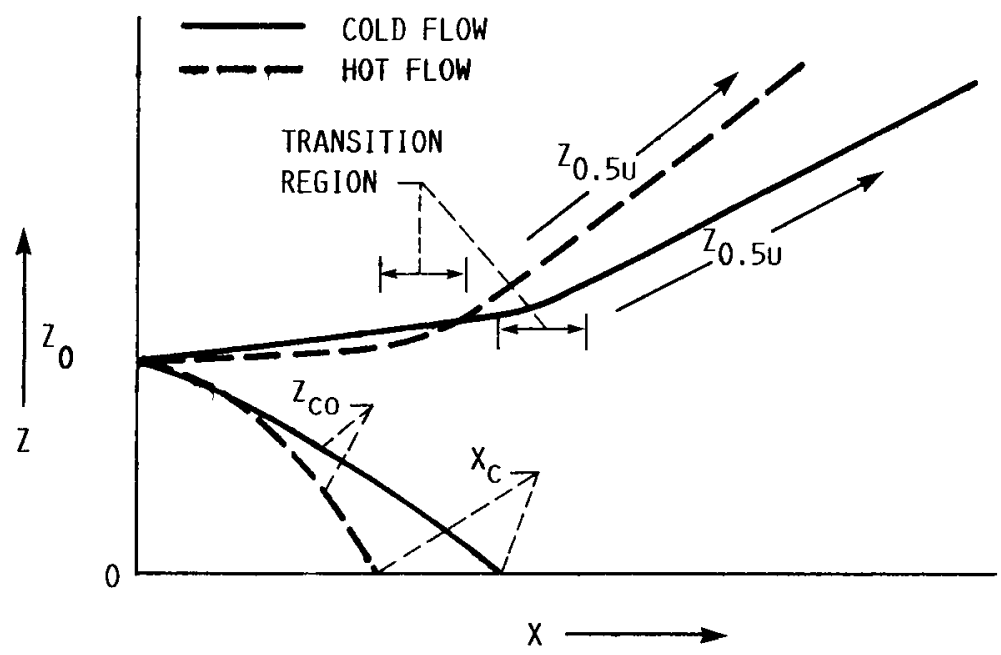

FIGURE 10. - SCHEMATIC SKETCH OF REPRESENTATIVE 50PERCENT VELOCITY CONTOURS AND ASSOCIATED CORE REGIONS. 


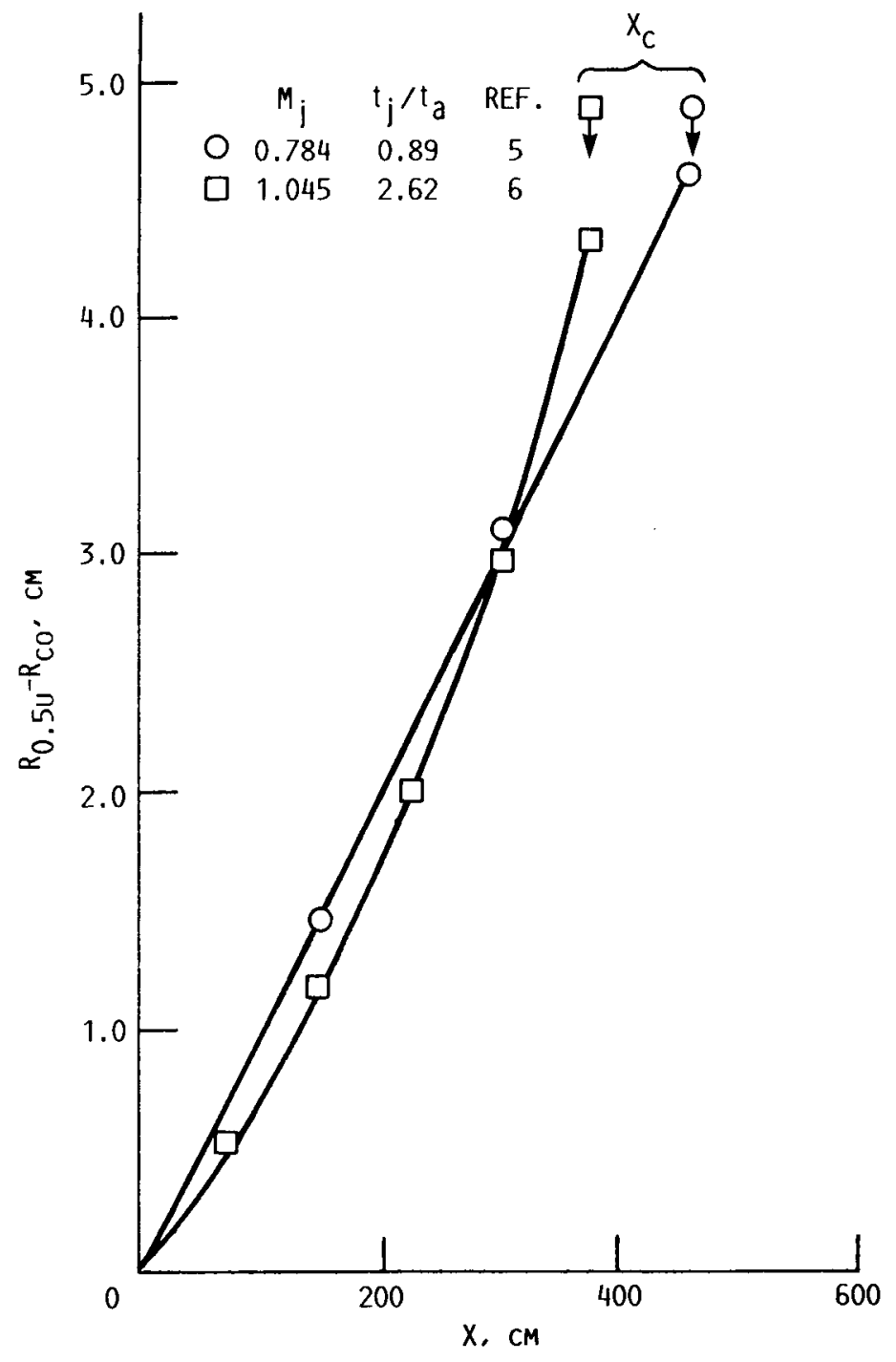

FIGURE 11. - VARIATION OF 50-PERCENT VELOCITY CONTOUR WITH AXIAL DISTANCE IN CORE REGION. CIRCULAR NOZZLE. 

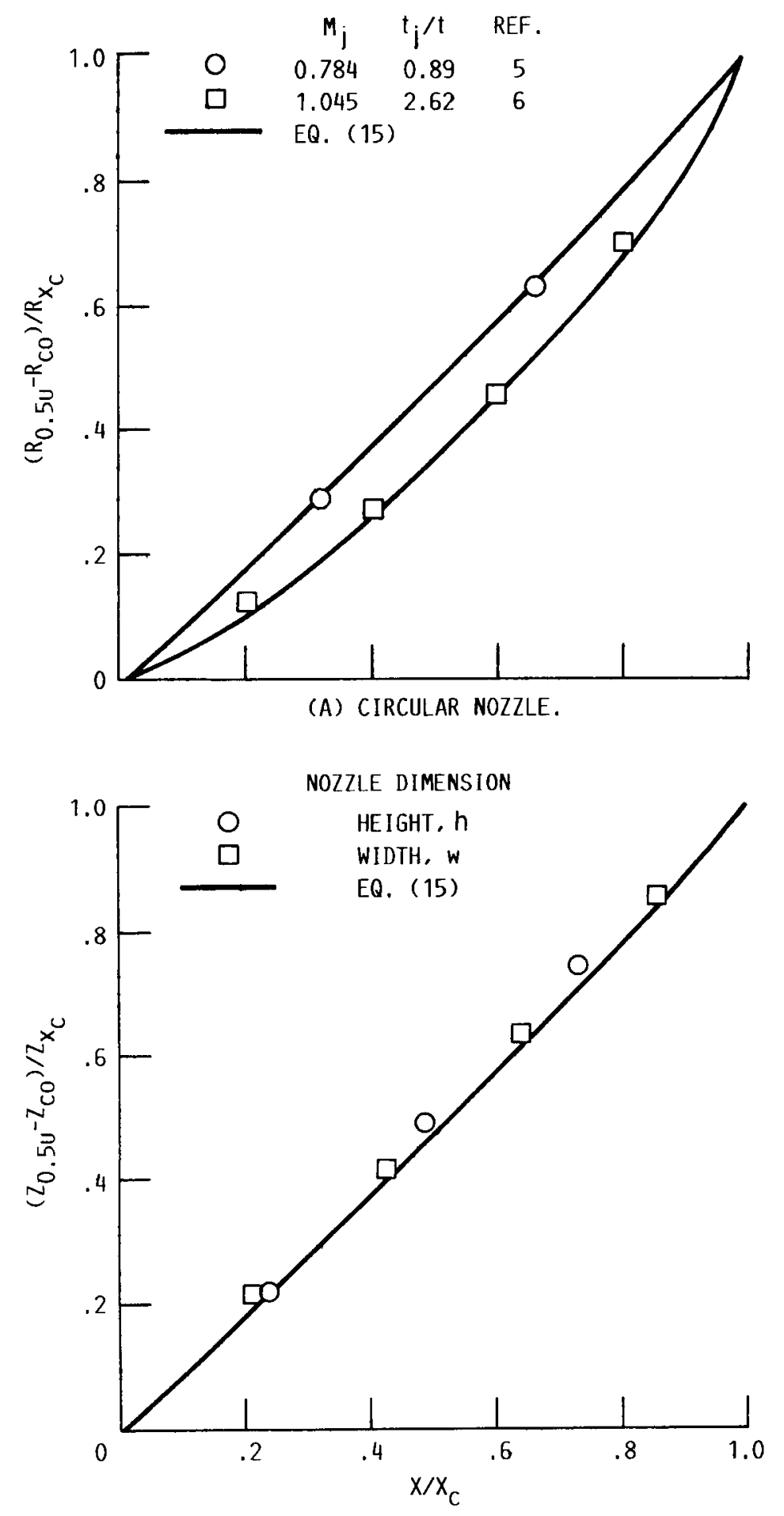

(B) RECTANGULAR NOZZLE (AR $=6), M_{j}, 0.784$;

$\mathrm{t}_{\mathrm{j}} / \mathrm{t}_{\mathrm{a}} \cdot 0.89$; REF. 5.

FIGURE 12.- 50-PERCENT VELOCITY CONTOUR CORRELATION IN CORE REGION. $D_{P}, 7.62 \mathrm{cM}$. 


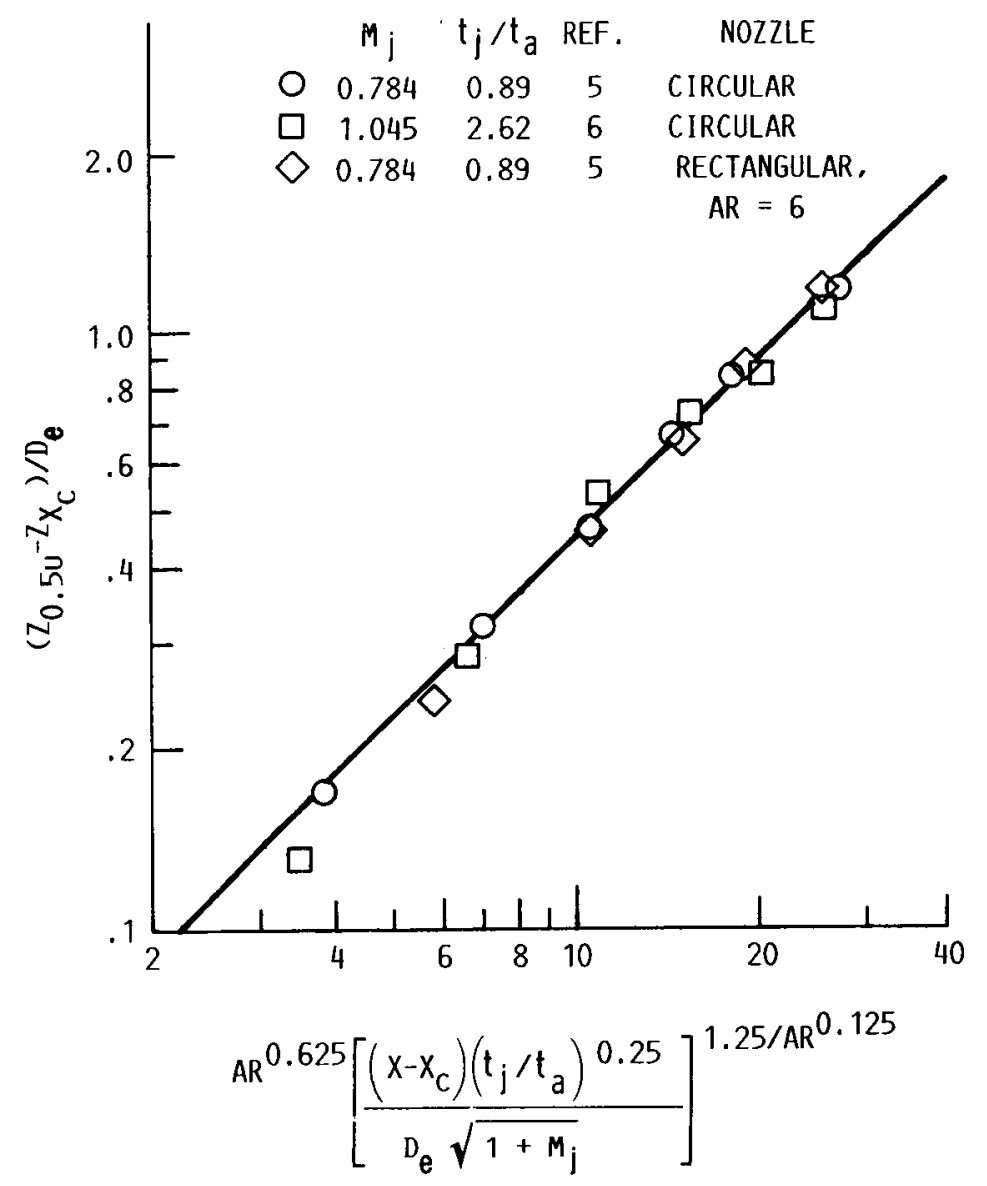

FIGURE 13. - CORRELATION OF TRANSITION REGION 50PERCENT VELOCITY CONTOUR DATA. $Z=R$ OR $h$. 


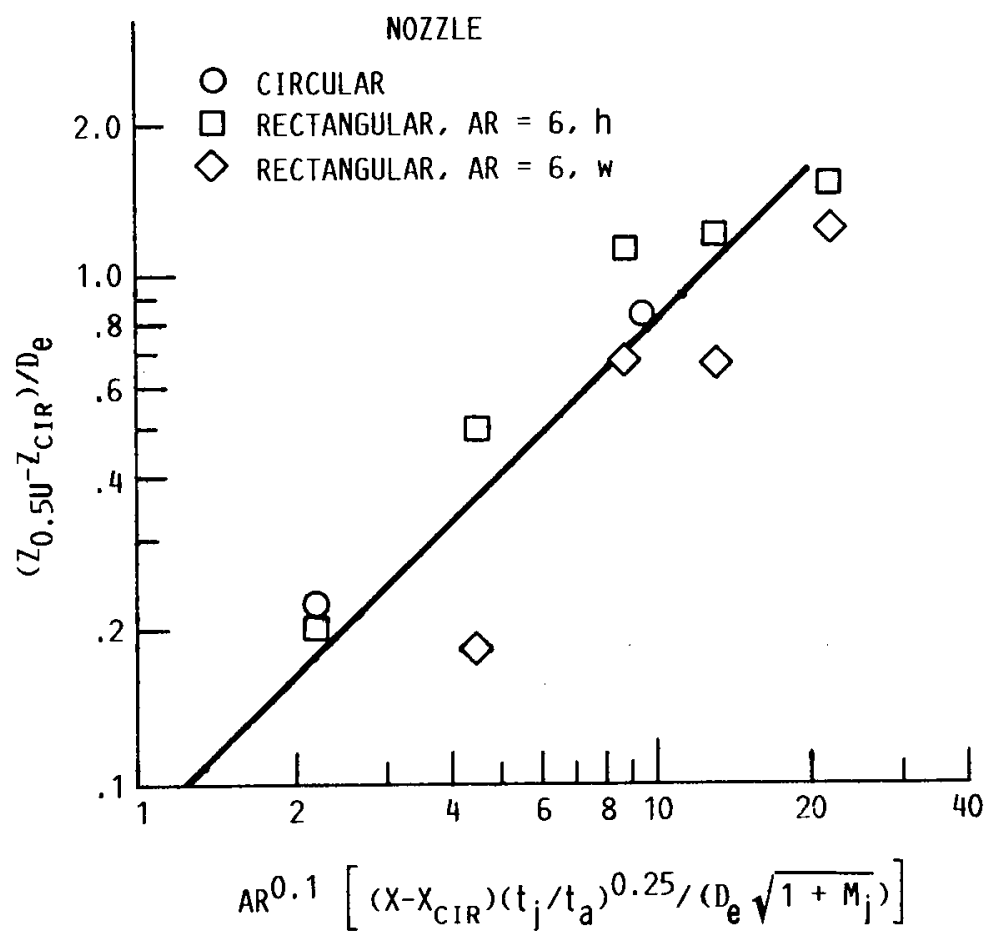

FIGURE 14. - CORRELATION OF COLD-FLOW FULLY-MIXED

REGION 50-PERCENT VELOCITY CONTOUR DATA. $M_{j}, 0.784$; $t_{j} / t_{a}, 0.89$; REF. 5 DATA.

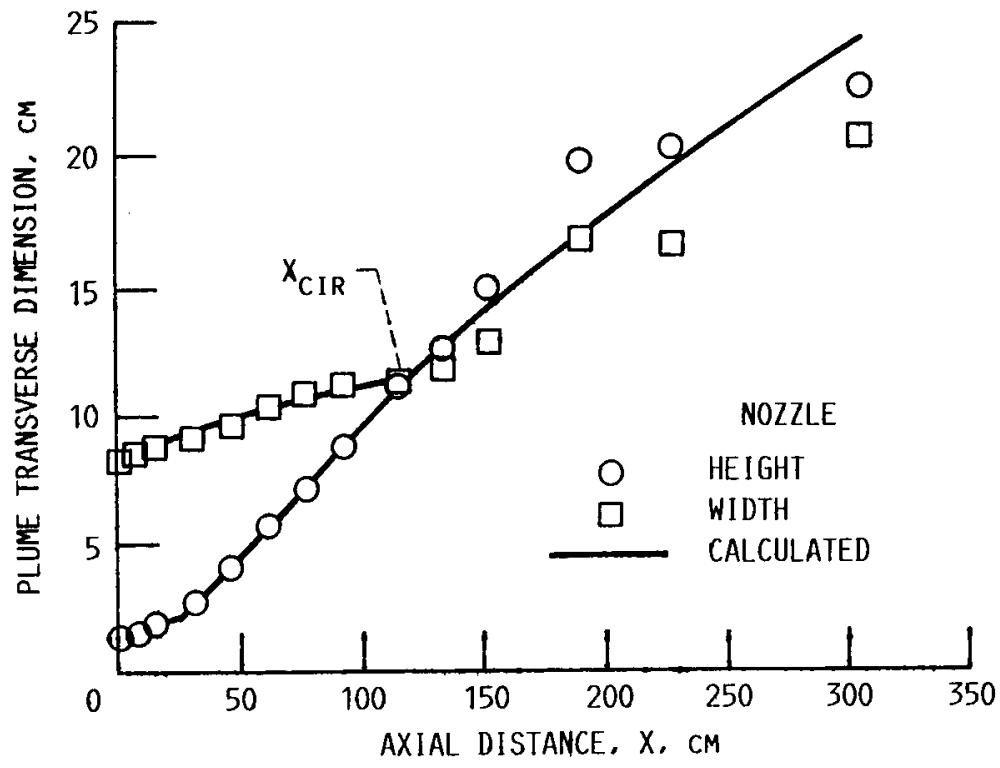

FIGURE 15. - COMPARISON OF MEASURED AND CALCULATED 50PERCENT VELOCITY CONTOURS FOR A RECTANGULAR NOZZLE. AR, $6.0 ; \mathrm{M}_{\mathrm{j}}, 0.784 ; \mathrm{t}_{\mathrm{j}} / \mathrm{t}_{\mathrm{a}}, 0.89 ; \mathrm{D}_{\mathrm{e}}, 7.62 \mathrm{cM} ; \mathrm{REF} .5$. 


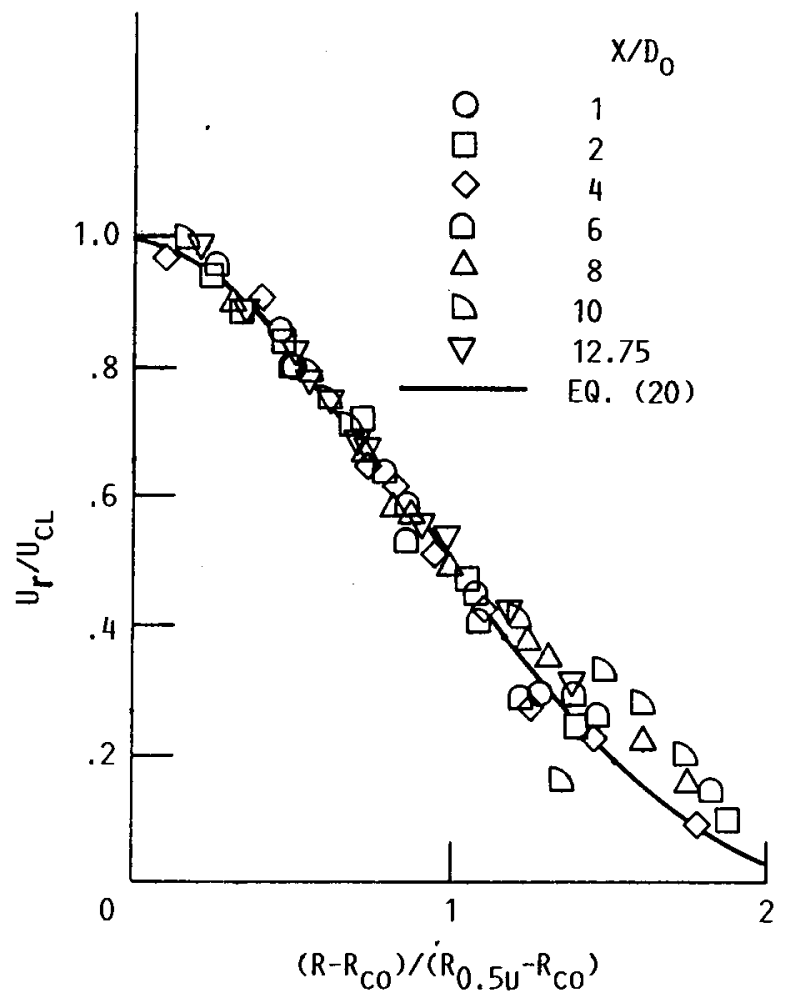

FIGURE 16. - TYPICAL SINGLE-STREAM TRANSVERSE PROFILES. CIRCULAR NOZZLE: $M_{j}$. $0.97: \mathrm{t}_{\mathrm{j}} / \mathrm{t}_{\mathrm{a}} \cdot 3.34: \mathrm{D}_{\mathrm{e}} \cdot 10.16 \mathrm{~cm}, \mathrm{REF} .4$ DATA. 


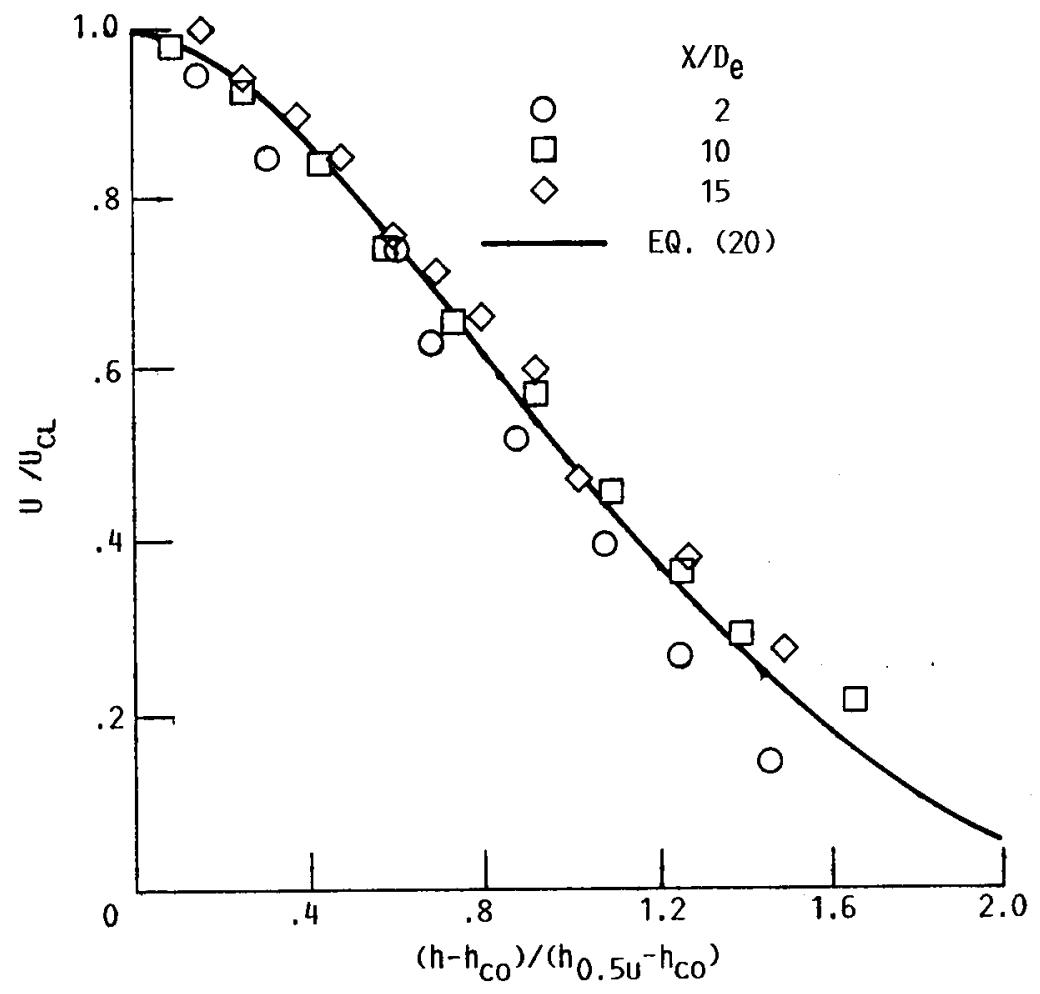

(A) NOZZLE HEIGHT.

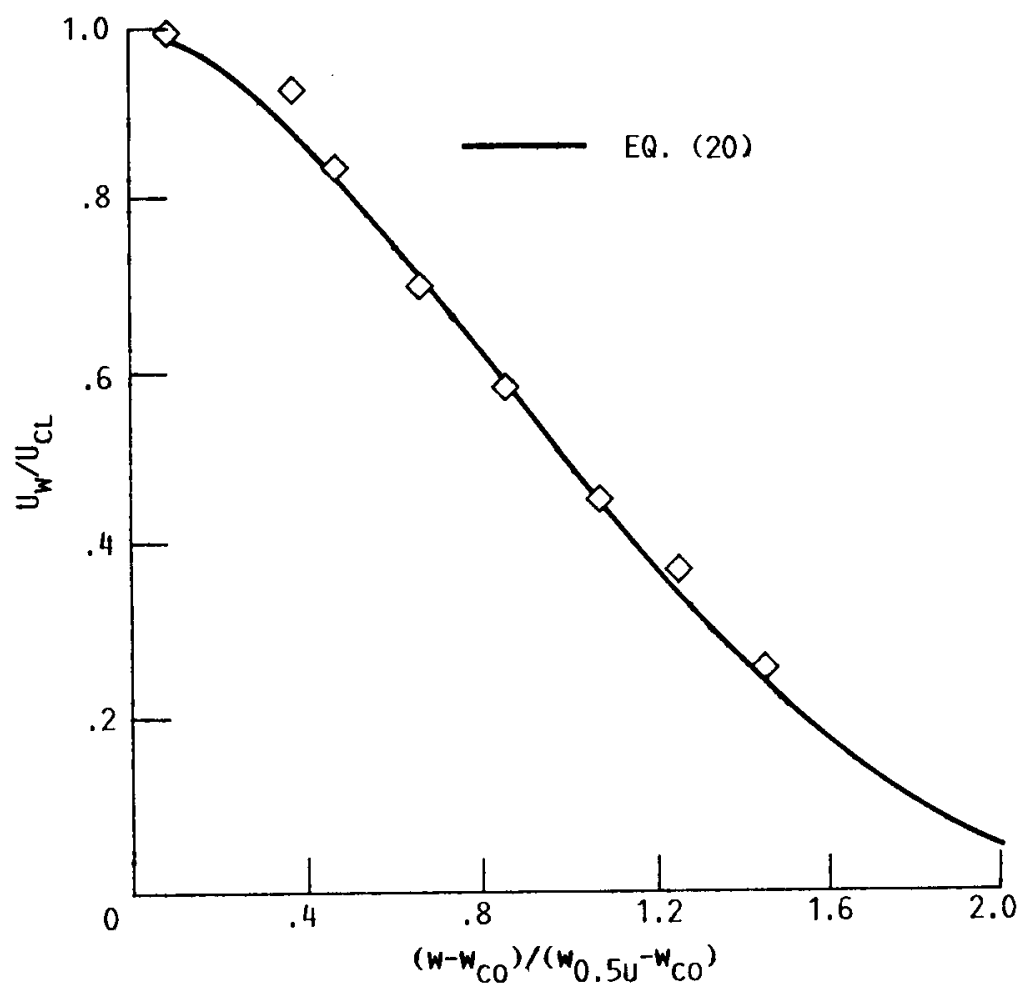

(B) NOZZLE WIDTH.

FIGURE 17. - RADIAL VELOCITY DECAY IN PLUME TRANSITION FLOW REGION OF A TWO-DIMENSIONAL NOZZLE. AR, $6: M_{j}$. 0.78: COLD FLOW: REF. 5 DATA. 

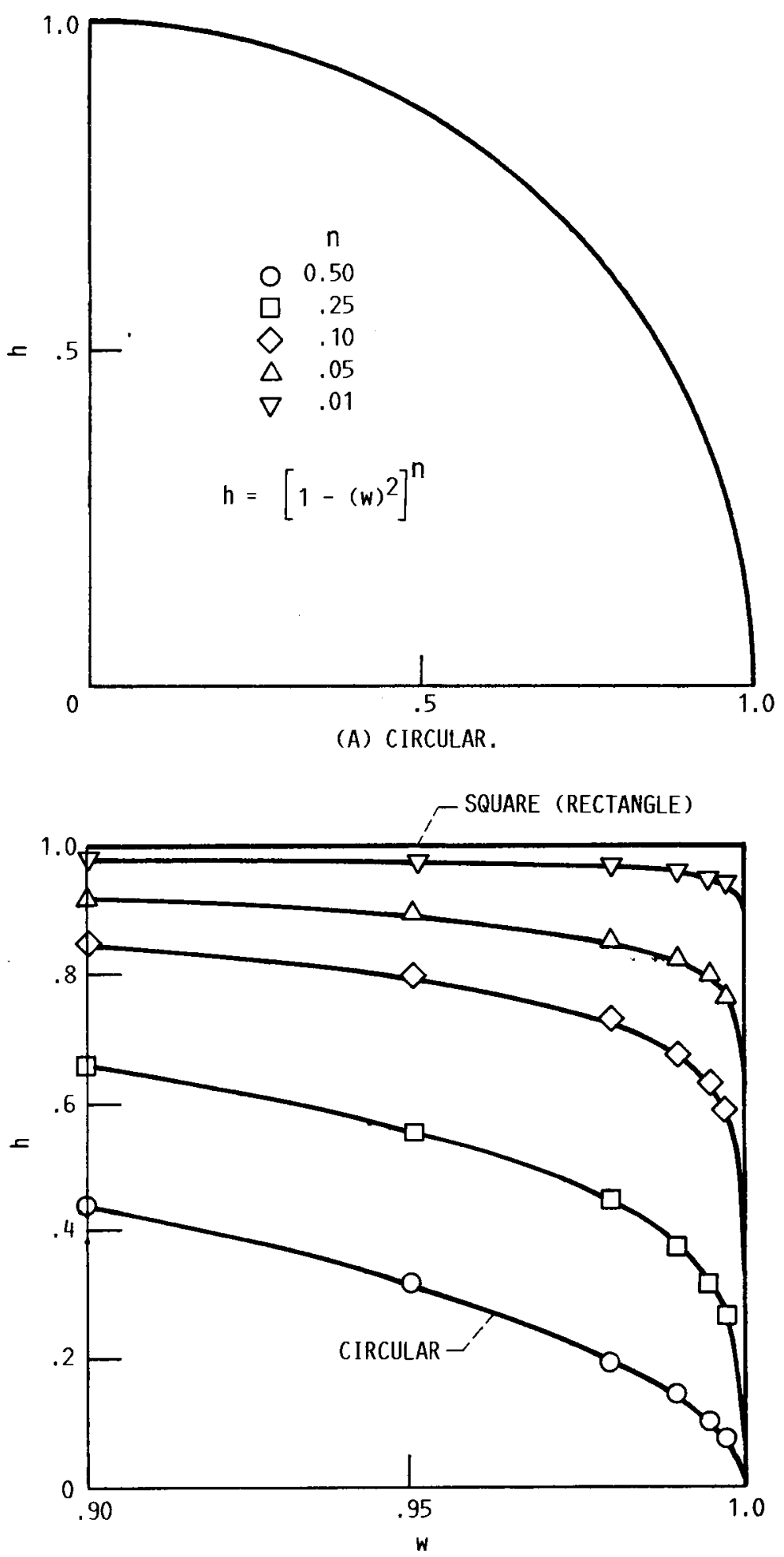

(B) SUPERELLIPSE.

FIGURE 18. - VARIATION OF SUPERELLIPSE SHAPE IN TRANSFORMATION OF SQUARE TO A CIRCLE FOR SEVERAL VALUES OF THE $n$-EXPONENT. 


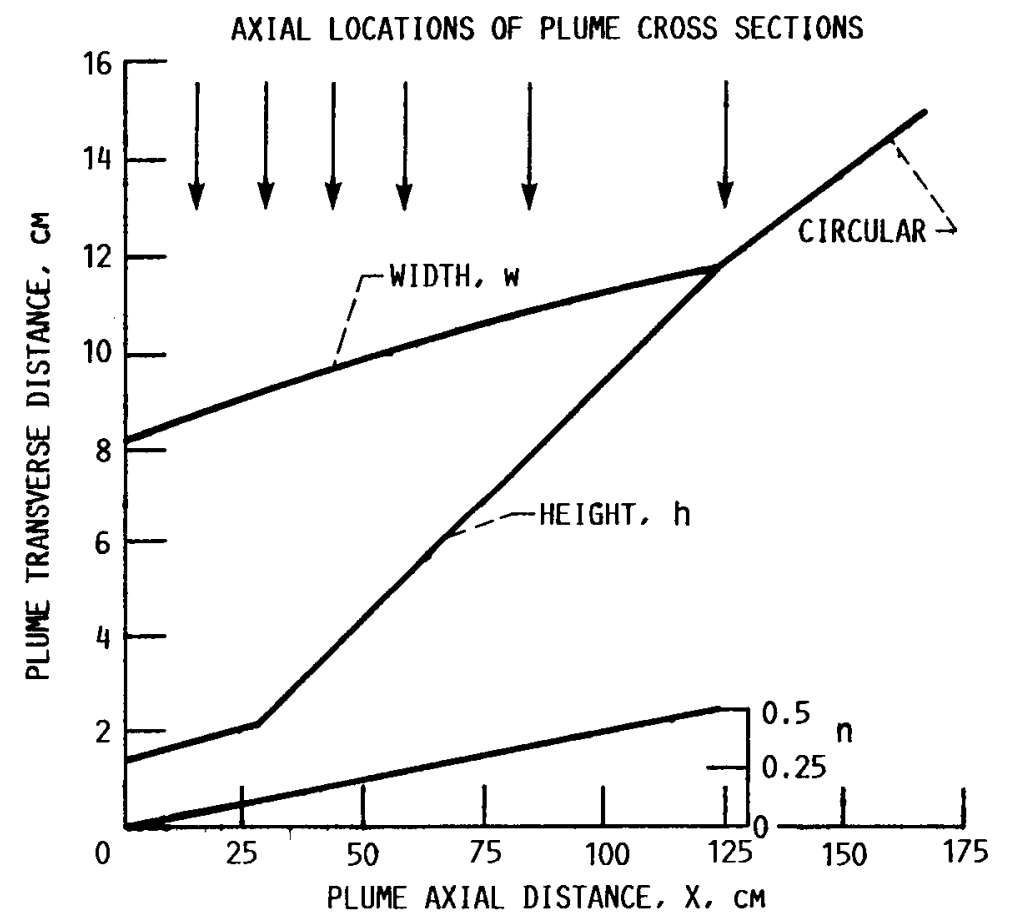

FIGURE 19. - CALCULATED 50-PERCENT VELOCITY CONTOURS AND $n$-EXPONENT AS FUNCTIONS OF AXIAL DISTANCE, $X$. AR, 6.0: $M_{j}, 0.784 ; D_{e}, 7.62 \mathrm{CM}$; COLD FLOW. 


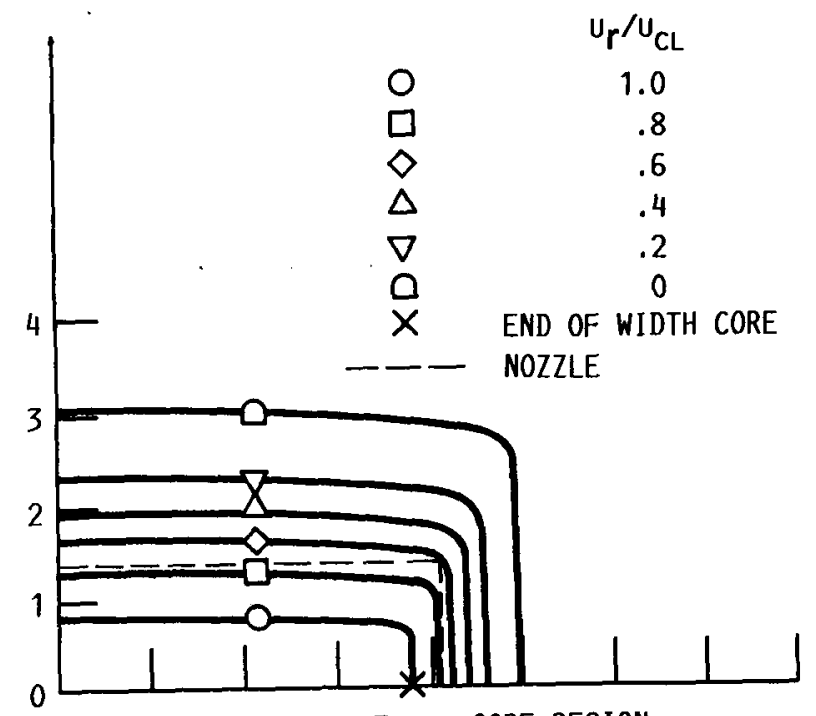

(A) $X=12.7 \mathrm{cM}$; CORE REGION.

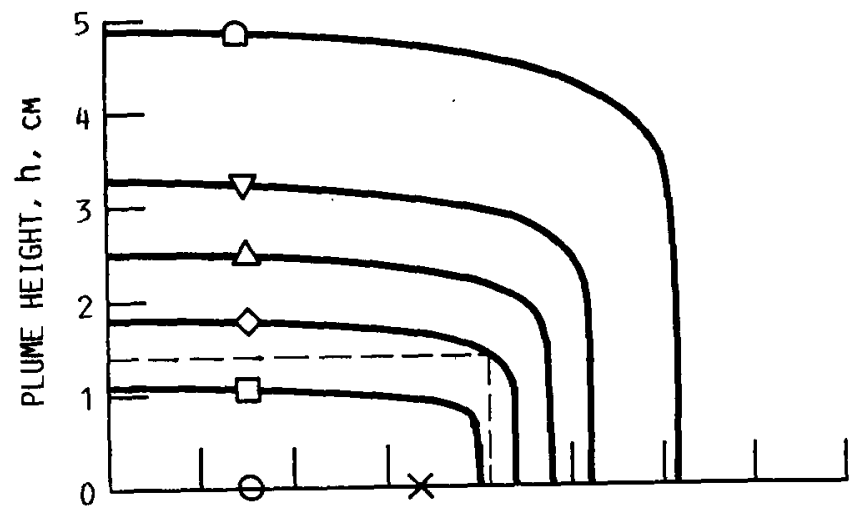

(B) $\mathrm{X}=27.34 \mathrm{cM}$; END OF HEIGHT CORE.

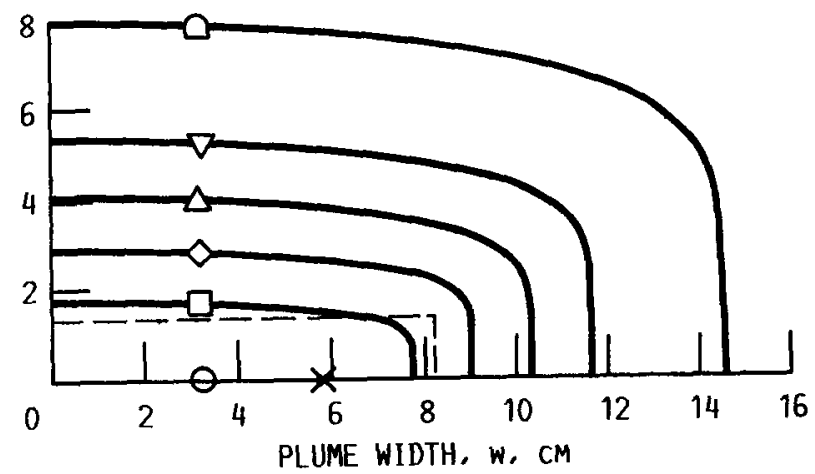

(C) $X=41.3 \mathrm{cM}$.

FIGURE 20. - REPRESENTATIVE CALCULATED PLUME VELOCITY CROSS SECTIONS AT SEVERAL AXIAL LOCATIONS FROM NOZZLE EXIT PLANE. COLD FLOW: $M_{j}, 0.784 ; D_{e}, 7.62 \mathrm{cM} ; A R, 6.0$. 

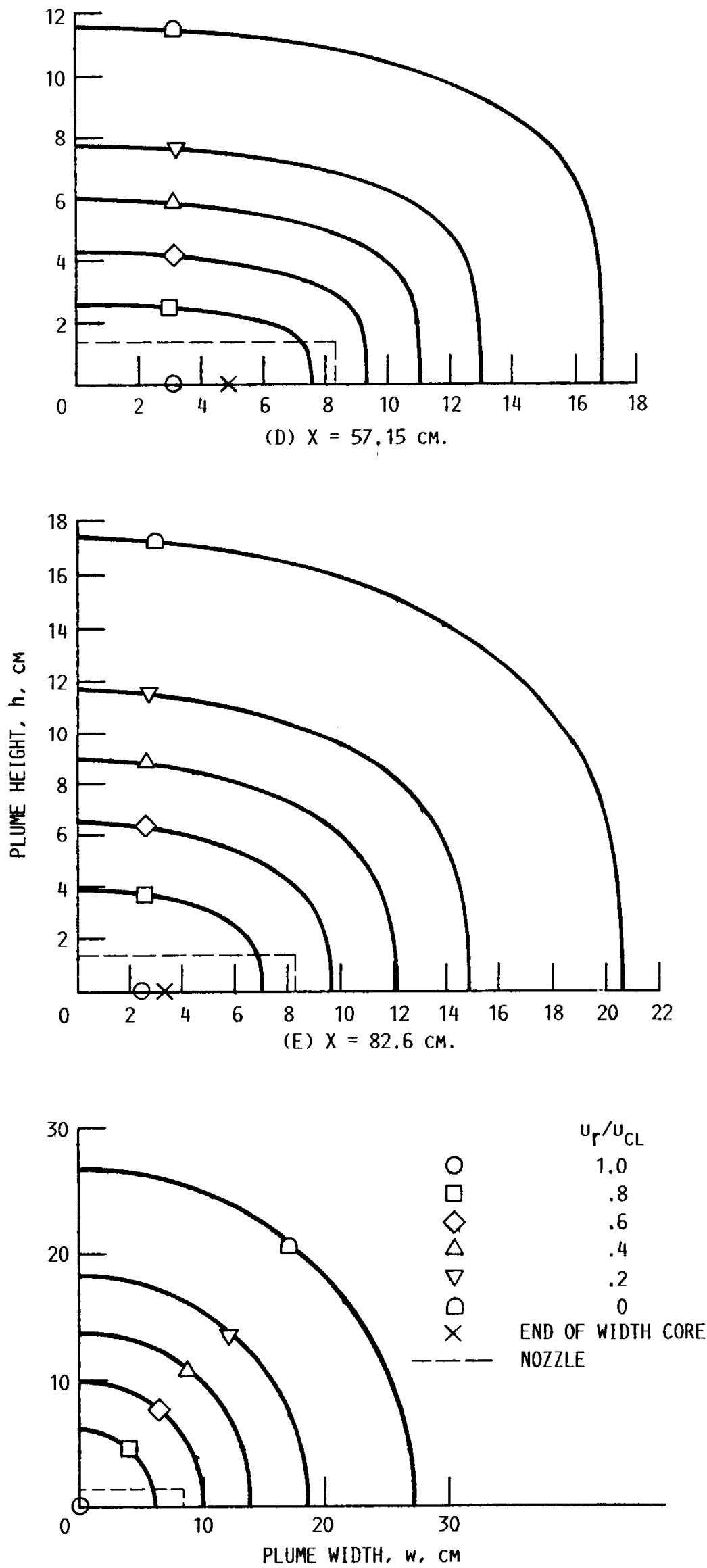

(F) $X=123.7 \mathrm{cM}$; CIRCULAR CROSS SECTION.

FIGURE 20. - CONCLUDED. 


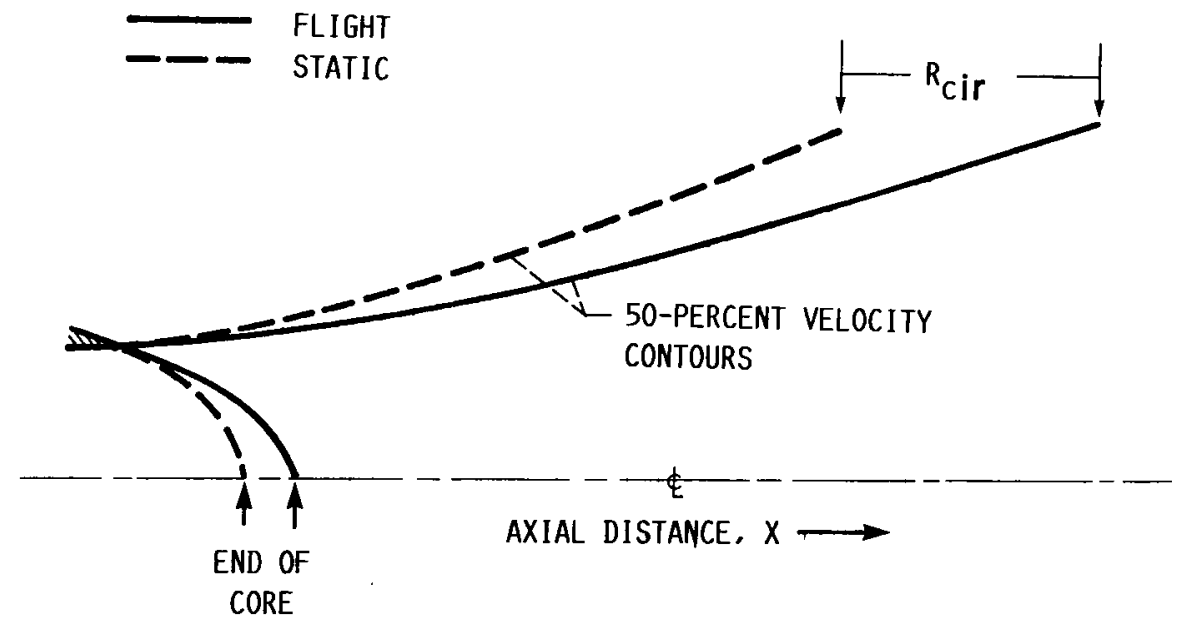

FIGURE 21. - SCHEMATIC SKETCH OF FLIGHT EFFECT ON CORE (HEIGHT DIMENSION) AND 50-PERCENT VELOCITY CONTOUR.

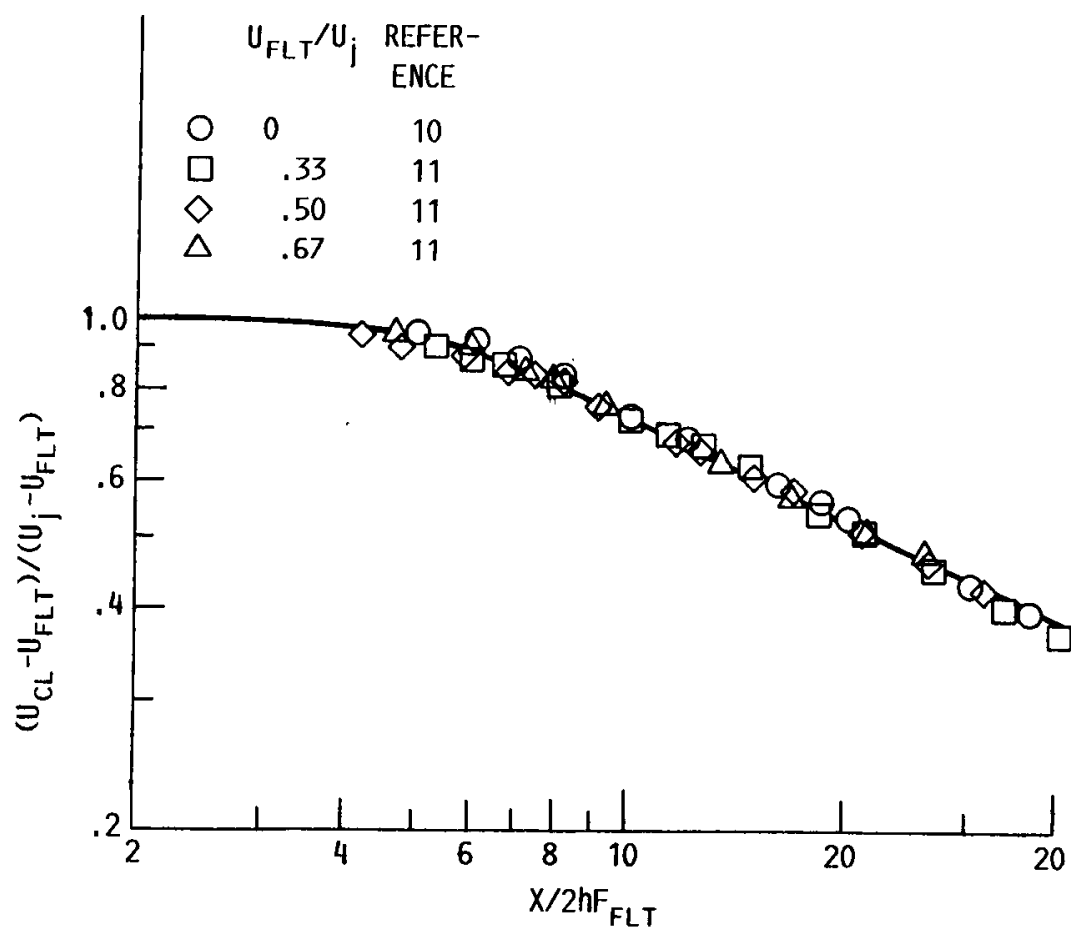

FIGURE 22. - CORRELATION OF FLIGHT EFFECT ON RECTANGULAR NOZZLE PLUME CENTERLINE VELOCITY DECAY. AR $=24 ;$ REF. 9. 


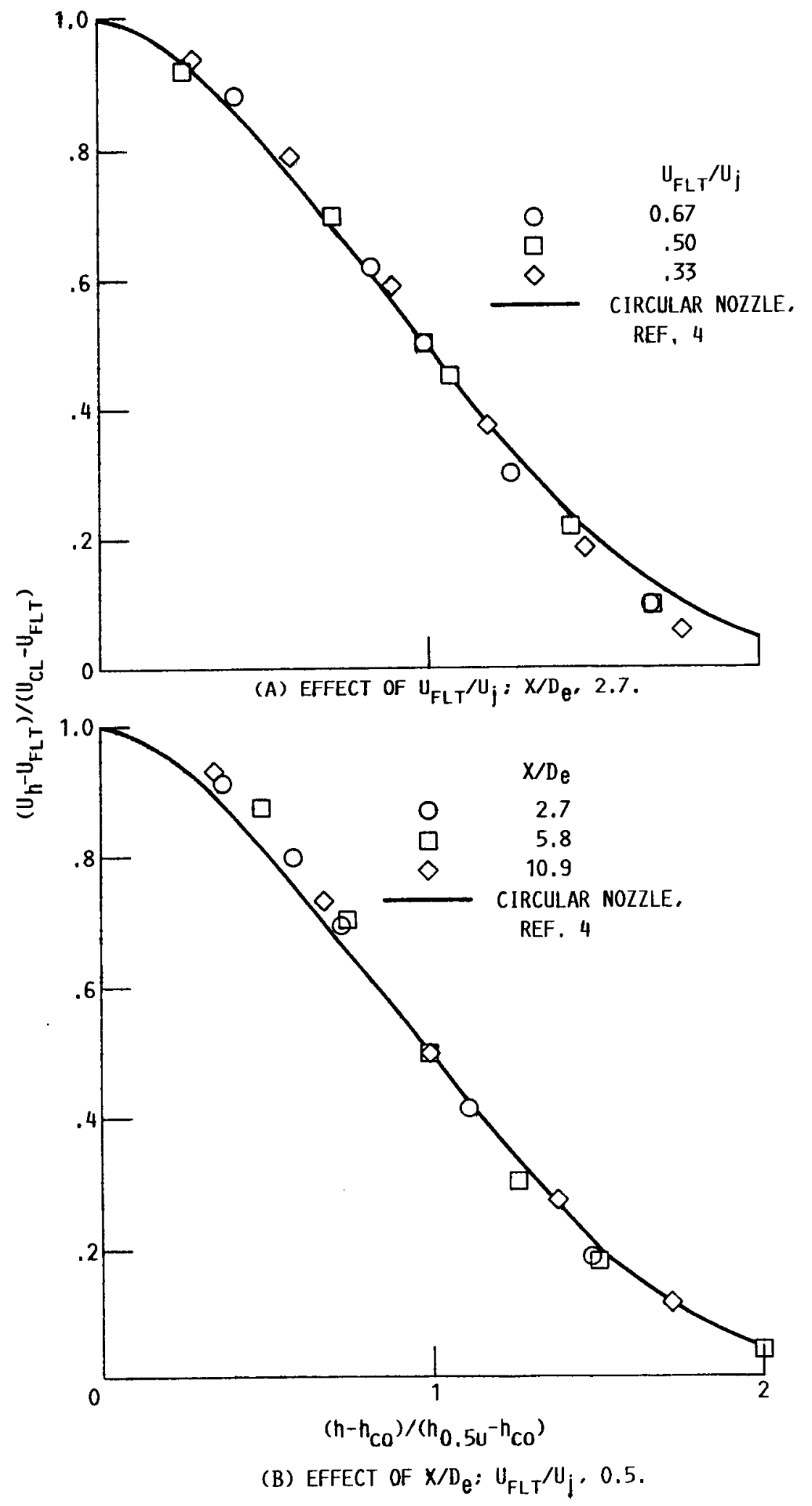

FIGURE 23. - REPRESENTATIVE RECTANGULAR NOZZLE PLUME TRANSVERSE VELOCITY DECAY IN NOZZLE HEIGHT (SHORT) DIMENSION WITH FLIGHT EFFECT. AR, 24; REF. 11 DATA. 


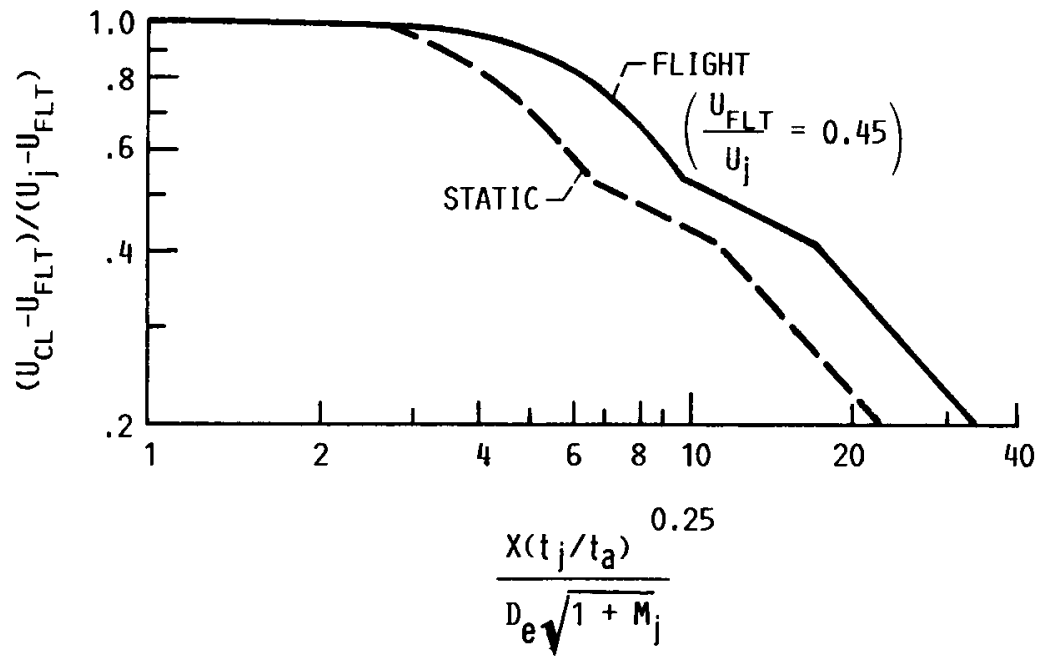

FIgURE 24. - CALCULATED PLUME CENTERLINE VELOCITY DECAY FOR A RECTANGULAR NOZZLE WITH AND WITHOUT FLIGHT EFFECT. AR, 6.0, $M_{j}, 0.784$; COLD FLOW: $\left(X_{C}\right){ }_{F L T}=1.5\left(X_{C}\right)_{\text {STAT }}$.

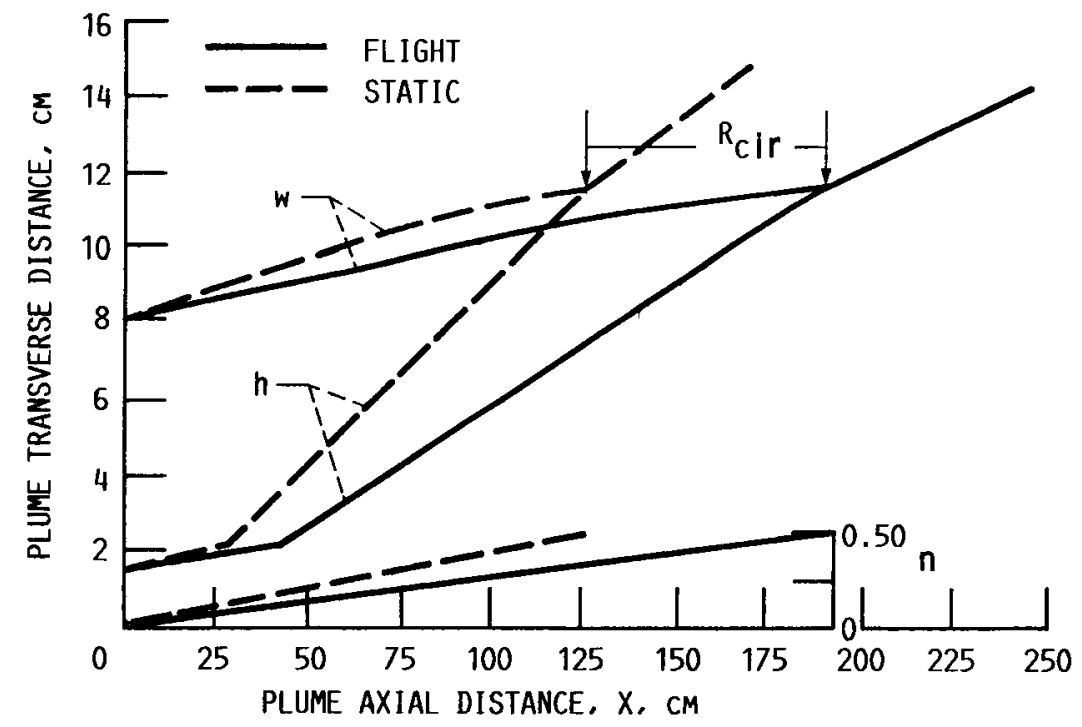

FIGURE 25. - COMPARISON OF REPRESENTATIVE CALCULATED PLUME 50-PERCENT VELOCITY CONTOURS AND EXPONENT $n$ WITH AND WITHOUT FLIGHT EFFECT. AR, $6.0 ; \mathrm{M}_{\mathrm{j}}, 0.784 ; \mathrm{D}_{\mathrm{e}}, 7.62 \mathrm{cM}$; COLD FLOW: $\left(X_{C}\right)_{F L T}=1.5\left(X_{C}\right)_{\text {STAT }}$. 


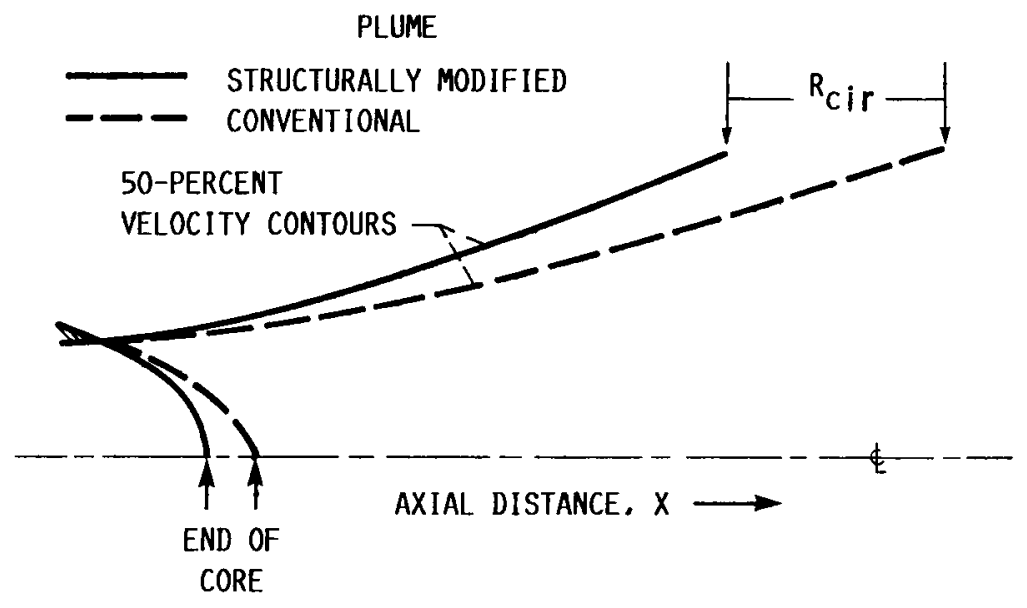

FIGURE 26. - SCHEMATIC SKETCH OF PLUME MODIFICATION EFFECTS ON CORE (HEIGHT DIMENSION) AND 50-PERCENT VELOCITY CONTOUR.

RECTANGULAR NOZZLE.

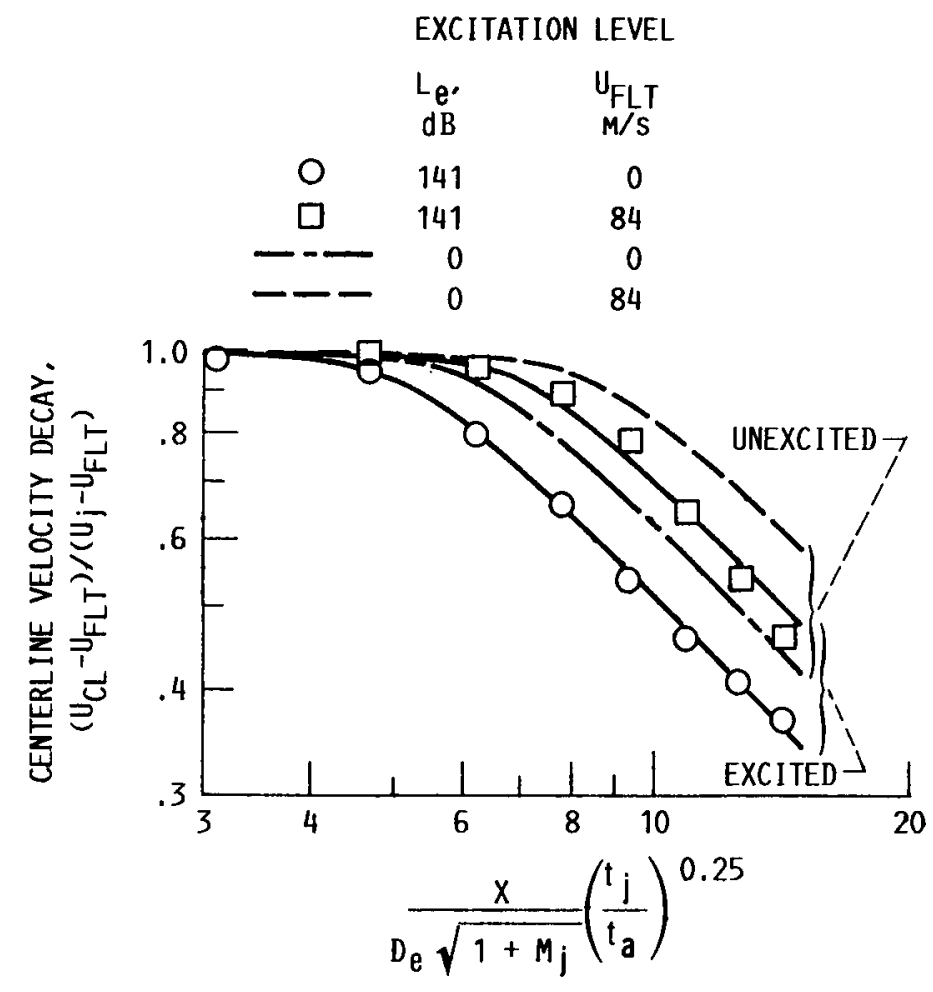

FIGURE 27. - EFFECT OF ACOUSTIC FLOW EXCITATION ON PLUME CENTERLINE VELOCITY DECAY WITH AND WITHOUT FLIGHT SPEED. $M, 0.58: D, 0.58 \mathrm{cM}$ : CIRCULAR NOZZLE: COLD FLOW: REF. 14 . 


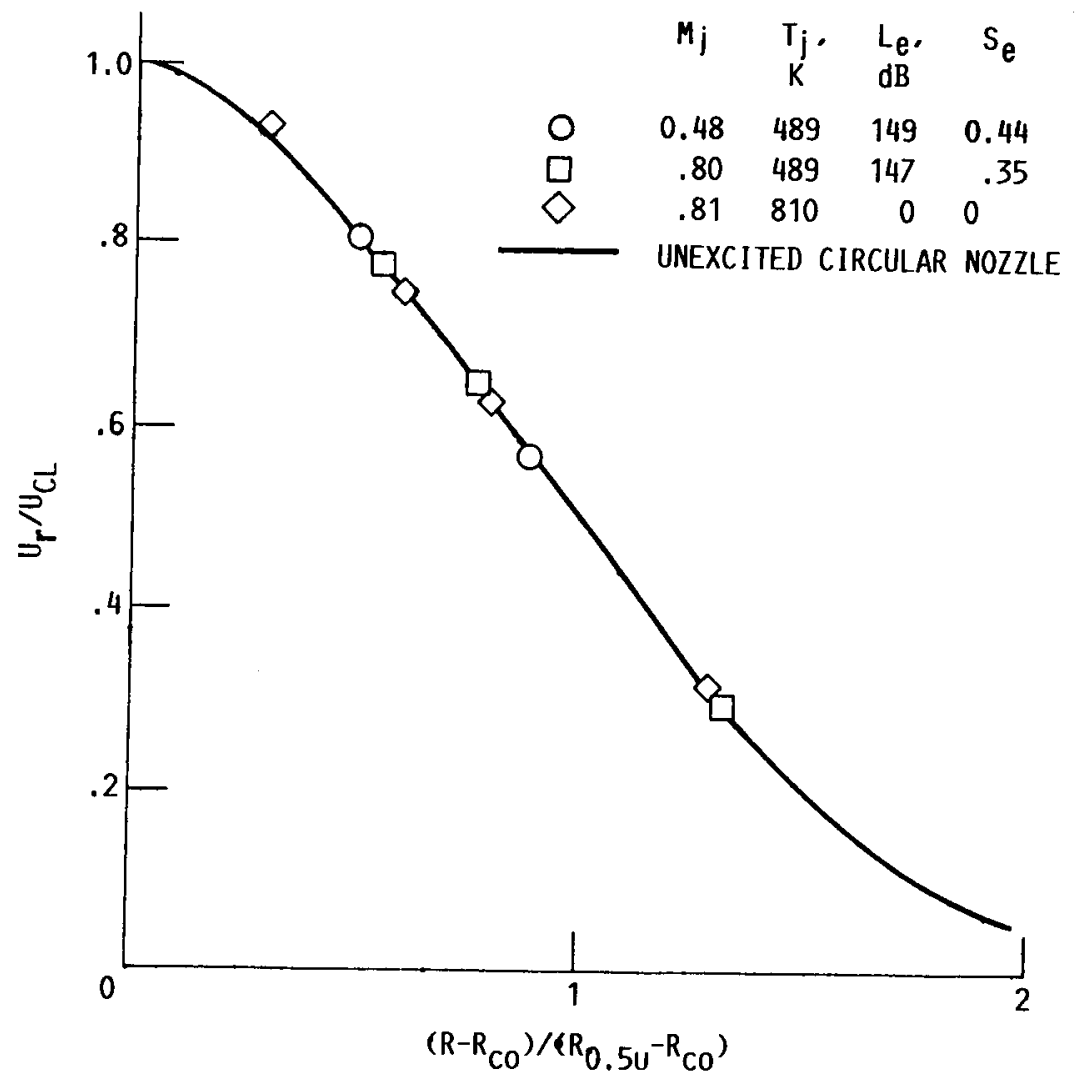

FIGURE 28, - REPRESENTATIVE PLUME RADIAL VELOCITY DECAY WITH AND WITHOUT ACOUSTIC EXCITATION. REF. $9 ; D_{e}, 5.08 \mathrm{~cm}$ : $X / D$ e 9: CIRCULAR NOZZLE.

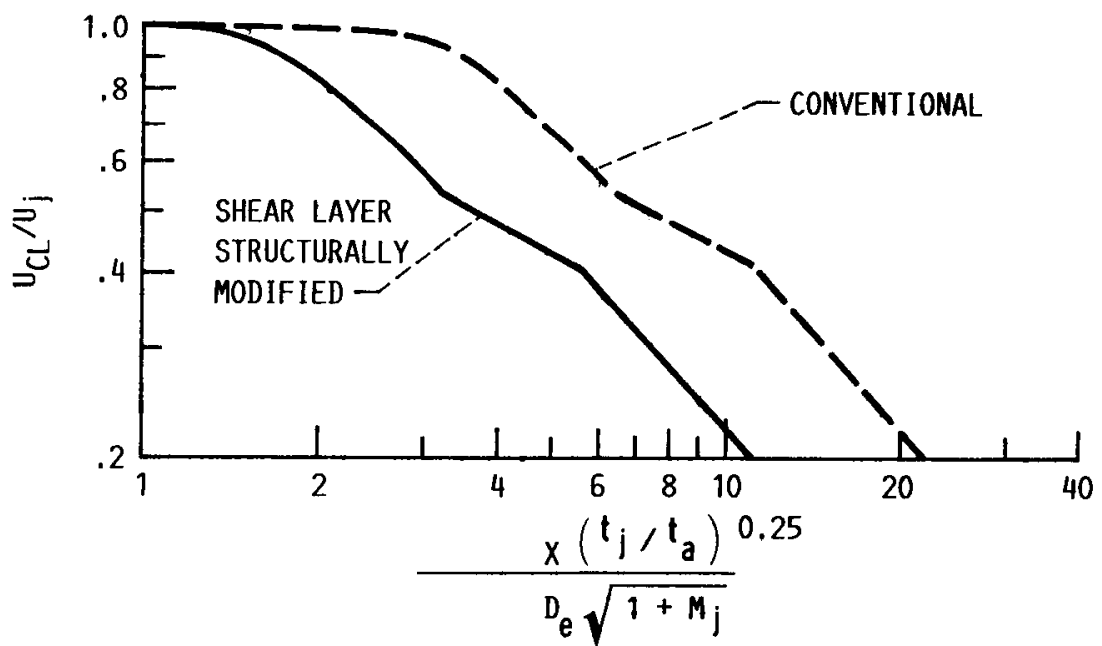

FIgURE 29. - TYPICAL EFFECT OF PLUME SHEAR LAYER STRUCTURAL MODIFICATION ON PLUME CENTERLIINE DECAY. RECTANGULAR NOZZLE $(A R, 6): X_{C, \text { MOD }}=0.5 X_{C}$, CONV 


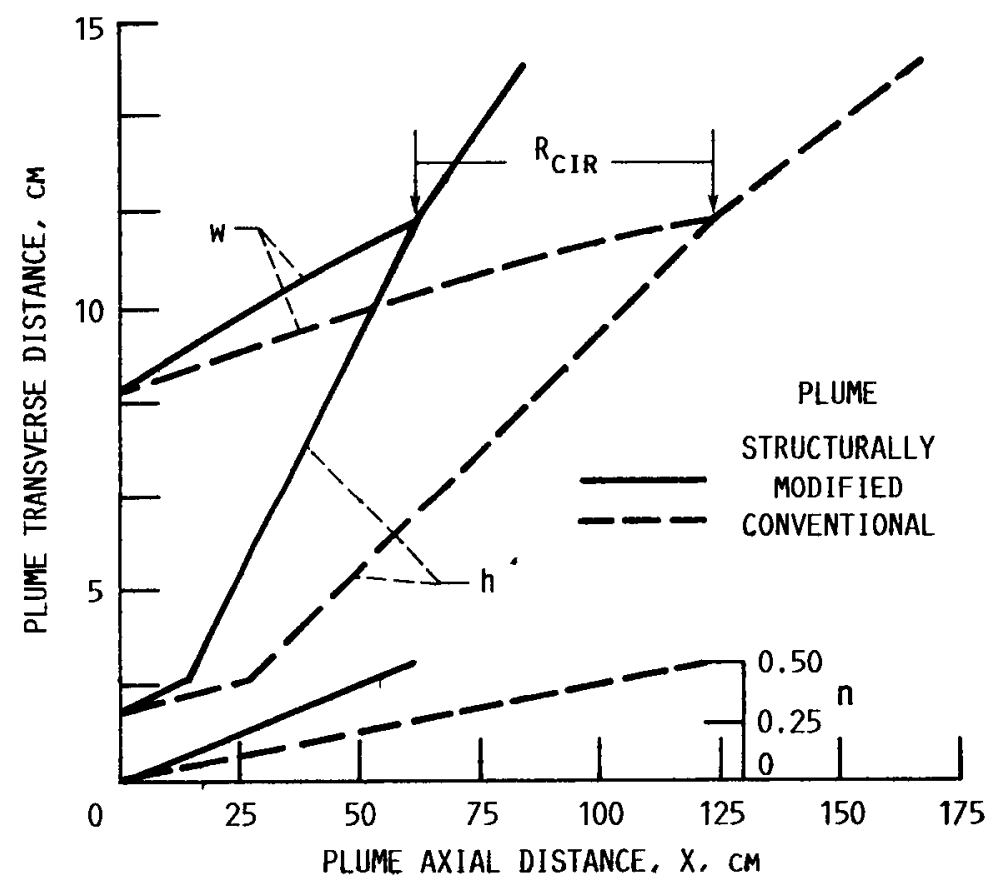

FIGURE 30. - COMPARISON OF REPRESENTATIVE CALCULATED RECTANGULAR NOZZLE 50-PERCENT VELOCITY CONTOURS AND n-EXPONENT WITH AND WITHOUT PLUME SHEAR LAYER MODIFICATION. STATIC CONDITIONS: $X_{C}$, MOD $=0.5 X_{C, \text { CONV }}$ 


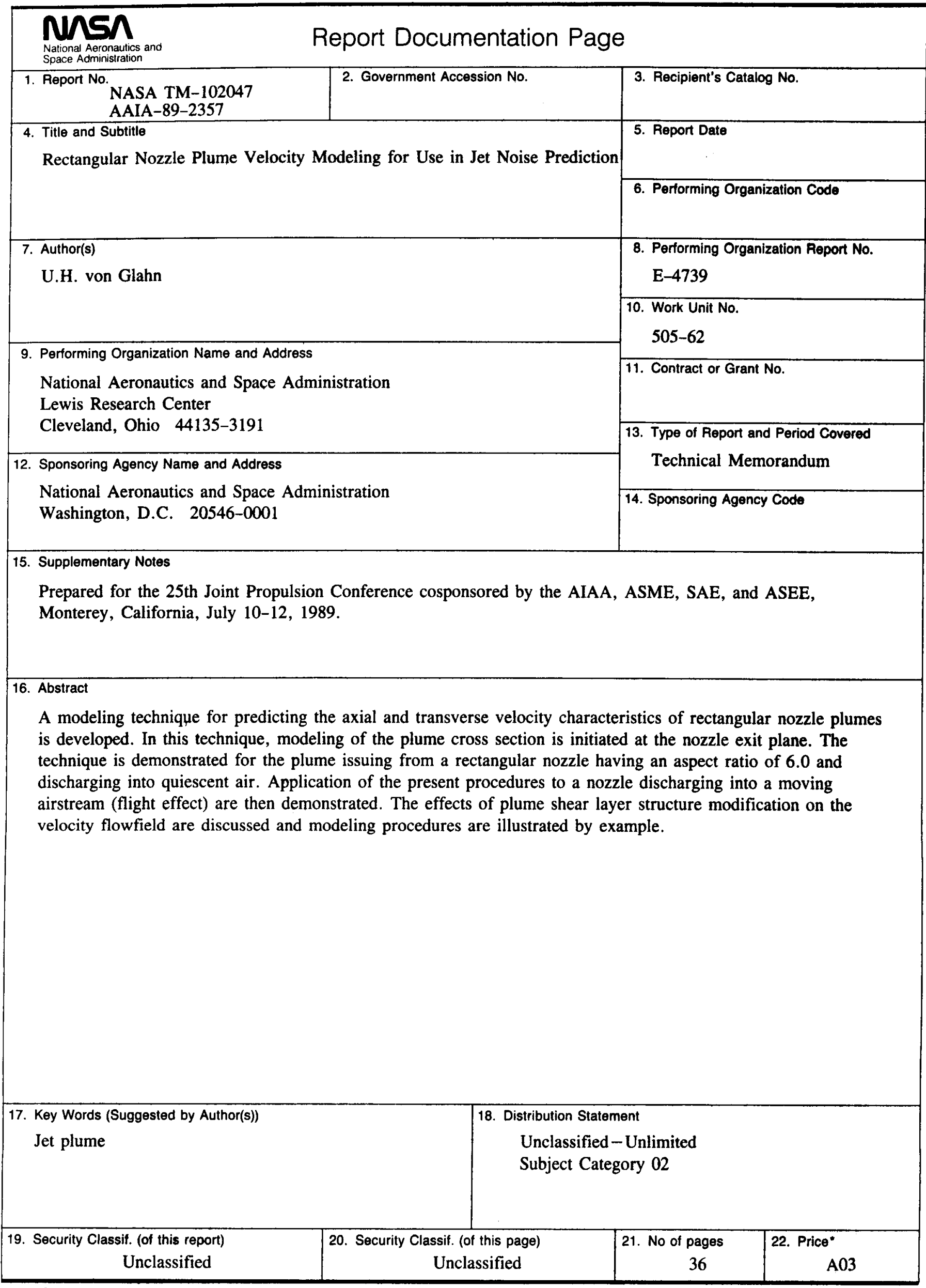

